\title{
Tracking mechanical Dauphiné twin evolution with applied stress in axial compression experiments on a low-grade metamorphic quartzite
}

\author{
Alexander Minor ${ }^{\mathrm{a}}$, Erik Rybacki ${ }^{\mathrm{b}}$, Manuel Sintubin ${ }^{\mathrm{a}, *}$, Sven Vogel $^{\mathrm{c}}$, Hans-Rudolf Wenk ${ }^{\mathrm{d}}$ \\ ${ }^{\text {a }}$ KU Leuven, Department of Earth and Environmental Sciences, Celestijnenlaan 200E, B-3001, Leuven, Belgium \\ b GFZ, Geomechanics and Rheology, Telegrafenberg, D-14473, Potsdam, Germany \\ ${ }^{c}$ LANCSCE, Los Alamos National Laboratory, Los Alamos, NM 87545, USA \\ ${ }^{\mathrm{d}}$ University of California, Berkeley, Department of Earth and Planetary Science, Berkeley, CA 94720, USA
}

\section{A R T I C L E I N F O}

\section{Keywords:}

Quartz

Mechanical Dauphiné twinning

EBSD

Neutron diffraction

Axial compression experiment

Paleostress indicator

\begin{abstract}
A B S T R A C T
The stress-dependent evolution of mechanical Dauphiné twinning has been investigated in axial compression experiments on a low-grade metamorphic quartzite, applying both time-of-flight neutron diffraction and electron backscatter diffraction. The data of the experimentally stressed quartzite samples were compared with those of the naturally deformed starting material to monitor Dauphiné twinning in relation to different experimental stress states. This comparison shows that in the experimental conditions of $500{ }^{\circ} \mathrm{C}$ temperature and $300 \mathrm{MPa}$ confining pressure, Dauphiné twinning initiates below $145 \mathrm{MPa}$ differential stress and saturates between $250 \mathrm{MPa}$ and $460 \mathrm{MPa}$ differential stress.

A single grain orientation analysis (SGOA) has been developed based on the distinction of quartz grains free of Dauphiné twin boundaries (DTBs) and containing Dauphiné twin boundaries. Comparing pole figures and inverse pole figures of DTB-free grains of the starting material with those of the experimentally stressed samples shows a significantly different orientation distribution of the positive $\{10 \overline{1} 1\}$ (r) and the negative $\{01 \overline{1} 1\}$ (z) rhombs. In DTB-containing grains, the SGOA allows to distinguish between host and twin domains. Using DTBfree grains, the SGOA furthermore reveals a particular pattern, with one of the $r$ rhomb maxima parallel to the axial compressive stress direction and a girdle with two $r$ rhomb submaxima perpendicular to it. We believe that this relationship between the axial compressive stress direction and the rhomb orientation distribution shows the potential of the SGOA in the reconstruction of the paleostress state in naturally stressed quartz-bearing rocks.
\end{abstract}

\section{Introduction}

Dauphiné twins can be a primary feature, formed during crystal growth (Leydolt, 1855; Frondel, 1962), or a secondary microstructure, resulting from transformation of hexagonal $\beta$ - to trigonal $\alpha$-quartz (Van Landuyt et al., 1986) or mechanical twinning. Mechanical Dauphiné twinning was discovered by hammering tests on single crystals (Schubnikov, 1930; Schubnikov and Zinserling, 1932). Since then it has also been documented in experimentally deformed polycrystalline quartz-bearing rocks (e.g. Tullis, 1970; Tullis and Tullis, 1972; Wenk et al., 2006), suggesting a direct relationship between Dauphiné twinning and the stress applied. Therefore, the question arises whether Dauphiné twins in quartz can be used as a paleostress indicator under geological conditions (e.g. Wenk et al., 2005; Wenk et al., 2011).

Most of these studies rely on a bulk crystallographic orientation distribution analysis (e.g. Tullis and Tullis, 1972; Lloyd, 2004; Wenk et al., 2006; Barton and Wenk, 2007). In this study, we introduce a single grain orientation analysis (SGOA) using electron backscatter diffraction, identifying the rhomb orientation distribution within the intracrystalline domains separated by Dauphiné twin boundaries (DTBs). We applied this novel procedure on a series of samples of a naturally deformed, low-grade metamorphic quartzite that were experimentally subjected to different axial compressive stresses. We subsequently explored how the occurrence of Dauphiné twins evolved in the experimentally stressed samples with respect to the Dauphiné twins that were already present in the starting material, reflecting the preceding geological history. Eventually, this experimental study allows us to assess the potential of Dauphiné twins as a paleostress indicator in naturally deformed quartz-bearing rocks.

\footnotetext{
* Corresponding author.

E-mail addresses: alexander.minor@kuleuven.be (A. Minor), uddi@gfz-potsdam.de (E. Rybacki), manuel.sintubin@kuleuven.be (M. Sintubin), sven@lanl.gov (S. Vogel), wenk@berkeley.edu (H.-R. Wenk).
} 

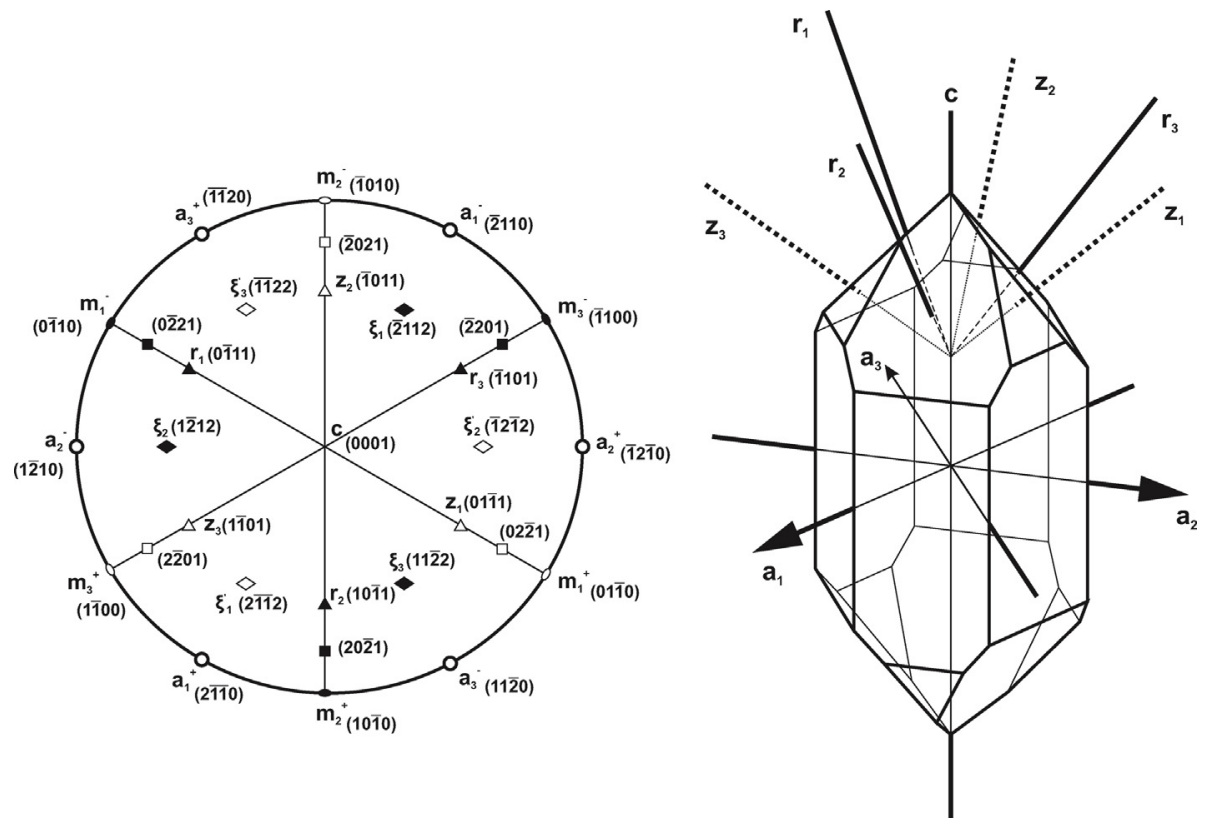

Fig. 1. Crystallographic stereographic projection of trigonal $\alpha$-quartz (left). Quartz crystal with indication of the c-axis and a-axes, and the poles to positive (r) and negative (z) rhomb planes (right).

\section{Dauphiné twinning in quartz}

Quartz has trigonal symmetry (spacegroup $P 3_{1} 21$ ) (Fig. 1). It can occur in a right-handed and left-handed form, which cannot be distinguished with diffraction methods. The Laue group for quartz is $3 \mathrm{~m}$. There are many twin laws for $\alpha$-quartz (e.g. Friedel, 1926). Of particular interest here is Dauphiné twinning where host and twin are related by a two-fold twin axis parallel to the crystallographic c-axis [0001]. In trigonal $\alpha$-quartz this $180^{\circ}$ rotation about the c-axis is equivalent to a $60^{\circ}$ rotation. Dauphiné twinning has no effect on the orientation of the crystallographic c-axis and a-axes, although the polarity of the a-axes [1120] $\left(\mathrm{a}^{+}\right.$and $\left.\mathrm{a}^{-}\right)$are reversed, affecting the piezoelectric properties of quartz (e.g. Frondel, 1945). Dauphiné twinning transposes, the positive $\{10 \overline{1} 1\}$ (r) and the negative $\{01 \overline{1} 1\}(\mathrm{z})$ rhombs. Dauphiné twinning does not result in significant macroscopic finite strain. Twin domains only differ from host domains by small atomic displacements on the scale of the interatomic spacing without breaking bonds (Schubnikov and Zinserling, 1932) (Fig. 2).

Because the c-axis orientation is identical in host and twin domain, Dauphiné twins are undetectable by optical microscopy. Only diffraction techniques (X-ray, electron, neutron) can resolve the trigonal symmetry, based on intensity differences of diffraction signals on positive and negative rhomb lattice planes. Recent investigations using a scanning electron microscope (SEM) equipped with an electron backscatter diffraction (EBSD) system have revealed that Dauphiné twins are common in many naturally deformed quartz-bearing rocks (e.g. Menegon et al., 2011; Fall et al., 2016).

Mechanical Dauphiné twinning of trigonal $\alpha$-quartz is driven by its highly anisotropic stiffness (e.g. Heyliger et al., 2003; Ohno et al., 2006). Fig. 3 illustrates the stiffness anisotropy at experimental temperature conditions $\left(500{ }^{\circ} \mathrm{C}\right)$ by the equal area projection of the Young's modulus (after Ohno et al., 2006). The direction of maximum stiffness, with a Young's modulus of $109 \mathrm{GPa}$, is oriented near the pole to the negative $\{01 \overline{1} 1\}$ (z) rhombs, while the direction of minimum stiffness, with a Young's modulus of $63 \mathrm{GPa}$, is oriented near the pole of the positive $\{20 \overline{2} 1\}$ rhombs. Mechanical Dauphiné twinning occurs in response to a stress applied, and can already occur at ambient temperatures (Schubnikov and Zinserling, 1932; Zinserling and Schubnikow, 1933). Studies show that temperature has a significant influence on the initiation of mechanical Dauphiné twinning. At ambient temperature,

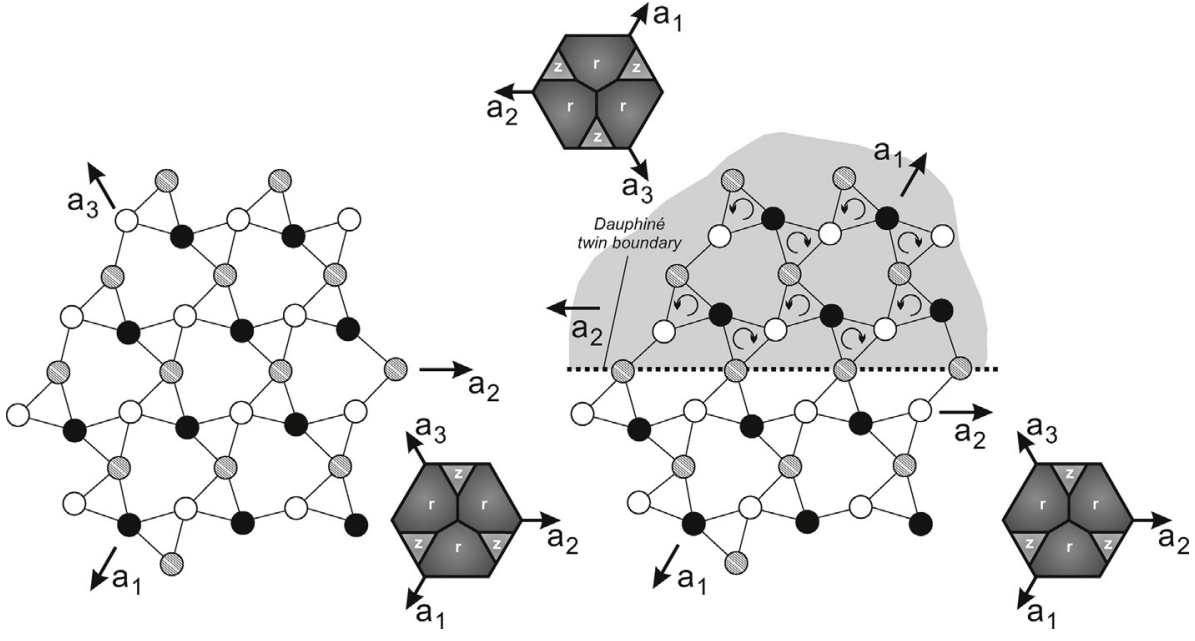

Fig. 2. Model of structure of trigonal $\alpha$-quartz without a DTB (left) and trigonal $\alpha$-quartz with a DTB (right), looking down the c-axis. Only silicon atoms are shown (circles); gray shades indicate different levels along c-axis; $\mathrm{a}_{1}, \mathrm{a}_{2}$ and $\mathrm{a}_{3}$ are crystallographic axes; $r$ and $z$ indicate the positive and negative rhomb planes, respectively. The DTB is indicated with dotted line; the twin with shaded background; the host with white background (after Schubnikov and Zinserling, 1932). 


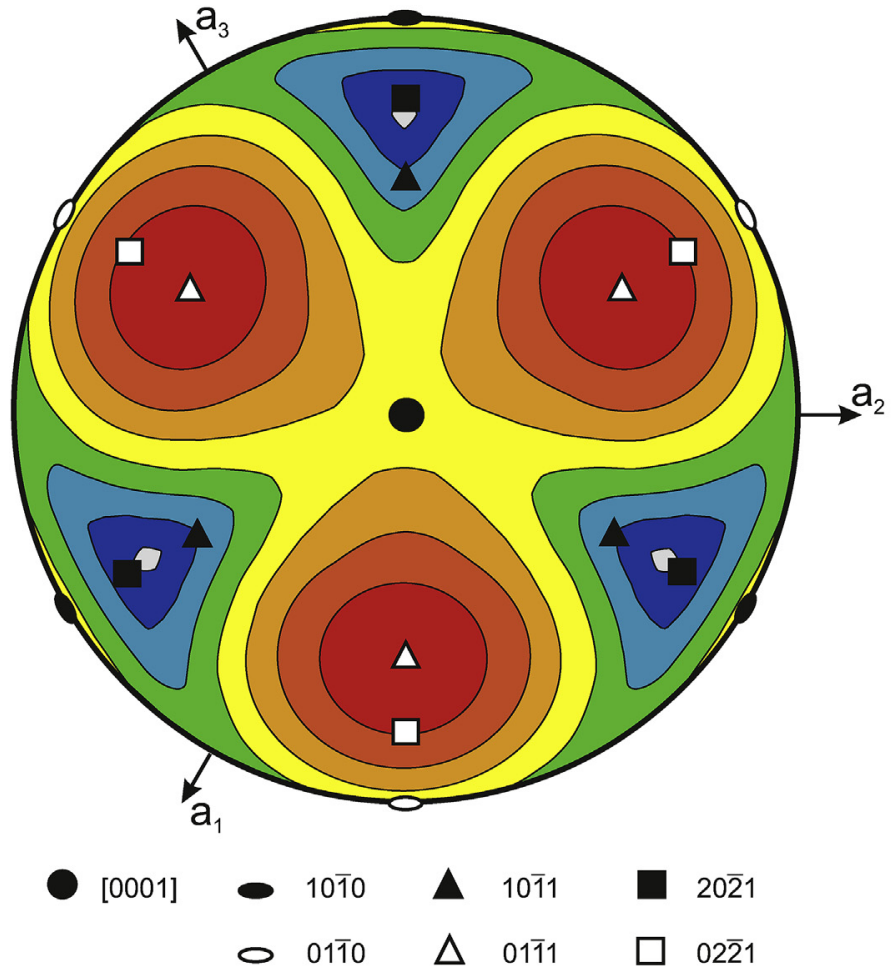

stresses of $50 \mathrm{MPa}$ are considered necessary to initiate twinning (Wenk et al., 2011), whereas at higher temperatures twinning is believed to occur at stresses less than $50 \mathrm{MPa}$ (Wenk et al., 2006; Tochigi et al., 2014).

In compression experiments, twinning is activated in a crystal when its stiff direction is parallel to the maximum compressive stress direction (Tullis, 1970). Orientations with a high stiffness, such as negative rhombs $\{01 \overline{1} 1\}(\mathrm{z})(109 \mathrm{GPa})$ and $\{02 \overline{2} 1\}$ (105 GPa), will twin to align orientations with a lower stiffness, such as positive rhombs $\{10 \overline{1} 1\}$ (r) $(73 \mathrm{GPa})$ and $\{20 \overline{2} 1\}$ ( $65 \mathrm{GPa})$, respectively, with the maximum compressive stress direction. Mechanical Dauphiné twinning induces a preferred orientation of the rhomb planes, while maintaining the original orientation distribution of c-axis and a-axes. Moreover, by twinning the crystal may become more 'deformable' through crystal-plastic deformation mechanisms (e.g. Lloyd, 2004; Menegon et al., 2011).

\section{Material and microstructural characteristics}

The axial compression experiments were performed on a naturally deformed, low-grade metamorphic quartzite (sample Br2 - Rio Grande, Alpinopolis, Brazil). This rock has previously been used in time-of-flight (TOF) neutron diffraction and electron backscatter diffraction (EBSD) experiments (Wenk et al., 2009). This quartzite contains mainly elongated quartz grains (Fig. 4). The quartzite also contains a minor amount of muscovite (length $\sim 50 \mu \mathrm{m}$ ). The orientation of the muscovite defines the foliation. Most of the muscovite is located between the quartz grains, but a part of the mica (only a few $\mu \mathrm{m}$ large) is found within the grains. The contact between the quartz grains and muscovite is mainly straight. The length of the quartz grains is varying between 100 and $200 \mu \mathrm{m}$ and the width between 20 and $50 \mu \mathrm{m}$ (measured with a petrographic microscope). The aspect ratio of the elongated quartz grains is about 4 to 1 . The quartz fabric shows a dominant shape preferred orientation with an angle of around $17^{\circ}$ to the foliation plane, defined by the orientation of the micas (Fig. 4). Already apparent in polarized light microscopy with an additional gypsum plate (Fig. 4b) is the wide range of c-axis orientations. Quartz grains show both high angle
Fig. 3. Highly anisotropic stiffness of quartz illustrated by the equal area projection of the Young's modulus (GPa). Calculated for the experimental temperature conditions $\left(500{ }^{\circ} \mathrm{C}\right)$ using isothermic elastic constants from Ohno et al. (2006). Linear scale. (For interpretation of the references to color in this figure legend, the reader is referred to the Web version of this article.)
QUARTZ

STIFFNESS $(\mathrm{GPa})$ boundaries $\left(>10^{\circ}\right)$ and low-angle boundaries $\left(<10^{\circ}\right)$. The size of the subgrains is around $10-20 \mu \mathrm{m}$ in diameter. Quartz shows undulose extinction. The grain boundaries are curved to serrated.

The microstructural analysis of the quartzite shows a deformation predominantly due to bulging with minor amount of subgrain rotation, which infers low-grade metamorphic condition with temperatures of around $300-400{ }^{\circ} \mathrm{C}$ (Lloyd and Freeman, 1994; Stipp et al., 2002), being lower than the temperature conditions $\left(500^{\circ} \mathrm{C}\right)$ of the axial compression experiments performed in this study. Nevertheless, both temperature conditions are sufficient to allow mechanical Dauphiné twinning even at low stresses of 50-100 MPa (Wenk et al., 2006). Also coarsegrained materials, like the quartzite used in this study, tend to be more favorable for twinning than fine-grained materials such as flint or novaculite (Wenk et al., 2007).

\section{Methodology and experimental setup}

Three cylinders (10 $\mathrm{mm}$ in diameter and $20 \mathrm{~mm}$ in length) were drilled perpendicular to the foliation from the quartzite sample for axial compression experiments in a Paterson type gas deformation apparatus (Paterson, 1970) at GFZ Potsdam. The experimental conditions were $500{ }^{\circ} \mathrm{C}$ temperature and $300 \mathrm{MPa}$ confining pressure during the whole experiment. These P-T conditions guarantee that all compression experiments are in the field of trigonal $\alpha$-quartz. At a temperature of $500^{\circ} \mathrm{C}$ DTBs are considered very mobile (Wenk et al., 2006).

The three cylinders, jacketed by a thin iron-sleeve to prevent intrusion of the argon pressure medium, were axially stressed with a differential stress of $145 \mathrm{MPa}, 250 \mathrm{MPa}$ and $460 \mathrm{MPa}$ for about $30 \mathrm{~h}$ each. For all samples, stressed in the experiments, just a minor elastic strain of $<0.4 \%$ was observed.

A standard petrographic microscope under plane parallel light, crossed polars and crossed polars with an additional gypsum plate, was used to study the microstructure in the starting material (Fig. 4) and the stressed samples to select the areas for further analyses. In the stressed samples no indications of any brittle deformation and minimal overall strain have been found in the fabric related to the axial compression experiments. 

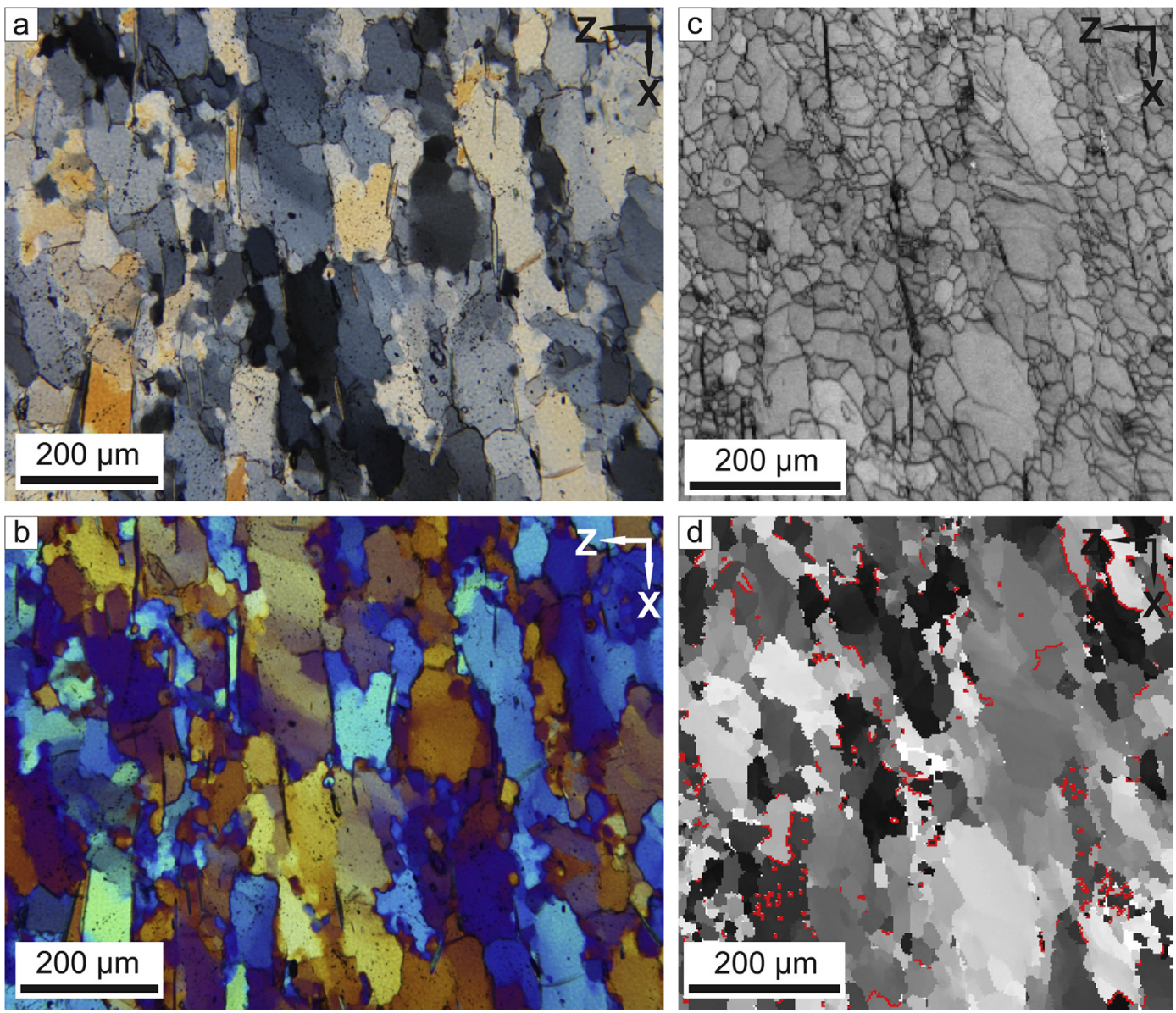

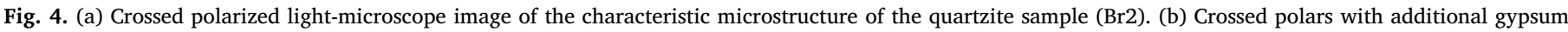

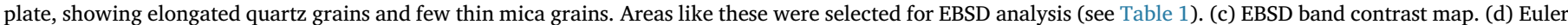

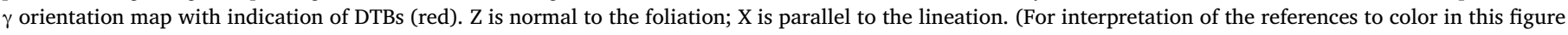
legend, the reader is referred to the Web version of this article.)

The quartz orientation distribution has been measured by both electron backscatter diffraction-orientation imaging microscopy (EBSDOIM) and time-of-flight (TOF) neutron diffraction. Comparing both bulk orientation distributions primarily aimed at validating the statistical significance of the EBSD orientation analysis with respect to the DTBs.

EBSD measurements were carried out with a Zeiss Evo scanning electron microscope equipped with a tungsten filament and a Digiview IV high resolution digital camera at UC Berkeley. EBSD has been performed on polished thin sections. The sections were cut orthogonal to the foliation and parallel to the lineation. Thin sections were made of the three stressed cylinders and of the original, non-stressed quartzite, serving as starting material. The coordinate system $\mathrm{XYZ}$ is based on the macroscopic fabric with $\mathrm{Z}$ normal to the foliation and $\mathrm{X}$ parallel to the lineation (Fig. 4). The mechanically polished thin sections were further polished using a colloidal silica suspension (SYTON) to guarantee a damage free surface for the SEM-EBSD analysis (cf. Fynn and Powell, 1979).

Full crystallographic orientations were obtained from automatically indexed EBSD patterns, assuming trigonal symmetry and the crystal structure of Antao et al. (2008), amcsd No. 0006212. We changed, though, the structure and atomic positions to match the right-handed space group $P 3_{1} 21$. Images with $696 \times 520$ resolution were binned $2 \times 2$. Scans used a square grid and an analytical step size between 2 and $5 \mu \mathrm{m}$, so each grain contains several measurement points. The SEM conditions for the automatic beam scans were $20-25 \mathrm{kV}$ accelerating voltage, vacuum of $\sim 10 \mathrm{~Pa}$, in variable pressure (VP) mode to avoid charging, 15-26 mm working distance and 50-100 $\mu \mathrm{A}$ beam current. A scan usually took between 8 and $10 \mathrm{~h}$. The angle between the incident beam and the normal to the sample surface was $70^{\circ}$.

Data collection and EBSD pattern indexing were performed with the TSL-OIM software. The EBSD data with orientations, confidence index (CI) and image quality (IQ) were then exported from the TSL-OIM software to BEARTEX v4.3 (Wenk et al., 1998) for mapping and identification of DTBs with the routine MAPTEX. The CI is a measure of pattern identification, where every measurement on the grid is assigned to a value between 0 and 1 depending on the reliability of the EBSD pattern indexing. High IQ is important for the unambiguous distinction between positive $\{10 \overline{1} 1\}$ and negative $\{01 \overline{1} 1\}$ rhombs which is done based on intensity differences, not positions. Points with a CI below 0.1, which are considered to be unreliable, and isolated spots were removed and replaced by the most common neighboring orientation of the four neighbors. However, there is still a possibility of misindexing if the IQ is low.

The EBSD data are presented as orientation maps. To define crystal orientations relative to sample coordinates, Euler angles $\alpha, \beta$ and $\gamma$ were used, corresponding to the Roe/Matthies convention (Wenk et al., 1998). The first two angles $(\alpha, \beta)$ define the $c$-axis rotation with respect to the sample reference system and $\gamma$ the a-axis rotation around the caxis (e.g. Fig. 4d).

Crystal orientations are plotted with the BEARTEX routine PING as pole figures and inverse pole figures. Pole figures (sample reference system) are presented for (0001) axis, and $\{11 \overline{2} 0\},\{10 \overline{1} 1\}$ and $\{01 \overline{1} 1\}$ poles. Inverse pole figures (crystal reference system) are presented for 


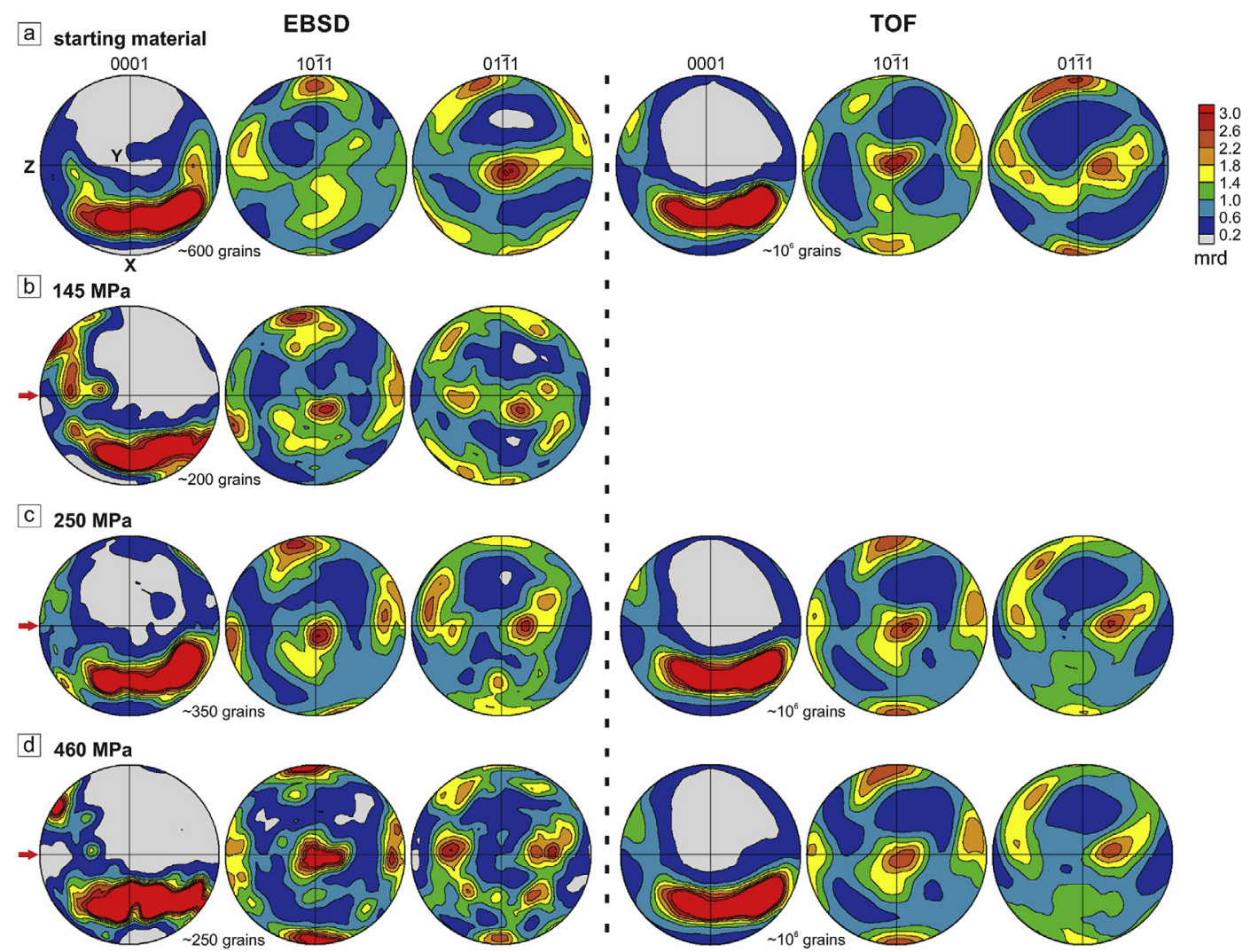

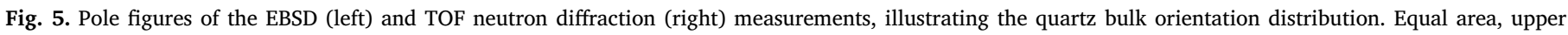

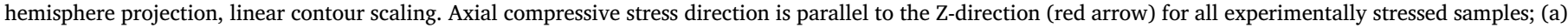

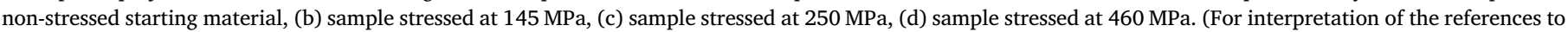
color in this figure legend, the reader is referred to the Web version of this article.)

the experimental axial compressive stress direction.

The samples were also measured with the neutron diffractometer HIPPO (High-Pressure-Preferred Orientation) at the Los Alamos Neutron Science Center (LANSCE). The advantage of the neutron diffraction analysis is that it allows the study of large sample volumes, representative of the bulk properties. The measured cylinders were $10 \mathrm{~mm}$ in diameter and $20 \mathrm{~mm}$ in length with a total volume of $\sim 1570 \mathrm{~mm}^{3}$. The neutron diffraction spectra were analyzed with the Rietveld method MAUD (Wenk et al., 2010).

\section{Results}

\subsection{Bulk orientation analysis}

Pole figures are presented for the starting material and the samples stressed at differential stresses of $145 \mathrm{MPa}, 250 \mathrm{MPa}$ and at $460 \mathrm{MPa}$ (Fig. 5), respectively. No neutron diffraction measurement has been performed on the sample stressed at $145 \mathrm{MPa}$. In all cases the axial compressive stress direction is parallel to the Z-direction, i.e. perpendicular to the foliation (Fig. 4).

For the EBSD data of the starting material, an asymmetric, broad and elongate, girdle-like c-axis orientation distribution is apparent (Fig. 5a). For the $r$ rhombs, apart from a maximum close to the X-direction, the orientation distribution is rather weak. For the $\mathrm{z}$ rhombs we can see a strong maximum ( $\sim 8 \mathrm{mrd}$ ) close to the Y-direction, and a secondary maximum near the $\mathrm{X}$-direction. The c-axis orientation distribution of the sample stressed at $145 \mathrm{MPa}$ is similar to that of the starting material (Fig. 5b). There are, however, three distinct $r$ rhomb maxima that are nearly at right angles to each other and close to the X-, $\mathrm{Y}$ - and Z-directions. A $\mathrm{z}$ rhomb minimum is apparent parallel to the Zdirection. The c-axis orientation distribution of the sample stressed at
$250 \mathrm{MPa}$ again does not show any changes with respect to the starting material (Fig. 5c). Also the $r$ rhomb maxima shifts slightly in orientation. The maxima are closer to the $\mathrm{X}$-, Y- and Z-directions, as in the case of the $145 \mathrm{MPa}$ sample. A $\mathrm{z}$ rhomb minimum is parallel to the Z-direction. The sample stressed at $460 \mathrm{MPa}$ shows again a slight shift in orientation for the c- and r-maxima. The orientation distribution of the z-maxima at $460 \mathrm{MPa}$ is similar as at $250 \mathrm{MPa}$, but the patterns are more irregular (Fig. 5d). There is, on the one hand, the asymmetric broad and elongate c-axis orientation distribution. Close to the X-, Yand $\mathrm{Z}$-directions three distinct $\mathrm{r}$ rhomb maxima occur. A clear $\mathrm{z}$ rhomb minimum is present parallel to the Z-direction.

In general, the orientation distributions for the TOF data are similar to those for the EBSD data (Fig. 5). The c-axis orientation distribution of the starting material is again characterized by an asymmetric, broad and elongate, girdle-like maximum with a maximum preferred orientation of about $10 \mathrm{mrd}$ (Fig. 5a). There is a distinct $r$ rhomb maximum in the Y-direction and two rather indistinct submaxima parallel to $\mathrm{Z}$ - and $\mathrm{X}$-direction. For the $\mathrm{z}$ rhombs, a maximum is present parallel to the X-direction, and a rather indistinct minimum parallel to the Zdirection. The c-axis orientation distribution of the sample stressed at $250 \mathrm{MPa}$ with a maximum preferred orientation of about $9 \mathrm{mrd}$, is similar to that of the starting material (Fig. 5c). However, the three $r$ rhomb maxima seem stronger, but still parallel to the $\mathrm{X}$-, Y- and Zdirections. An indistinct $\mathrm{z}$ rhomb minimum is still present in the Z-direction. A similar pattern can be observed for the sample stressed at $460 \mathrm{MPa}$, showing a c-axis orientation distribution with a maximum preferred orientation of about $8.5 \mathrm{mrd}$ (Fig. $5 \mathrm{~d}$ ). The orientation distribution of the $\mathrm{r}$ rhombs show three strong maxima close to the $\mathrm{X}$-, $\mathrm{Y}$ and $\mathrm{Z}$-direction. For the $\mathrm{z}$ rhombs a distinct minimum is present close to the Z-direction.

In contrast to the EBSD pole figures, the TOF pole figures are 


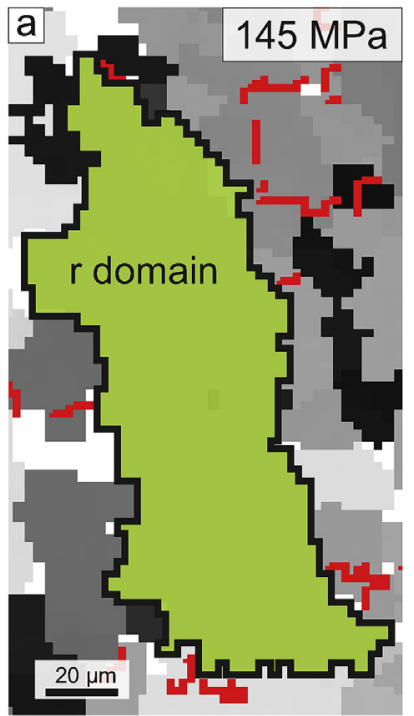

b
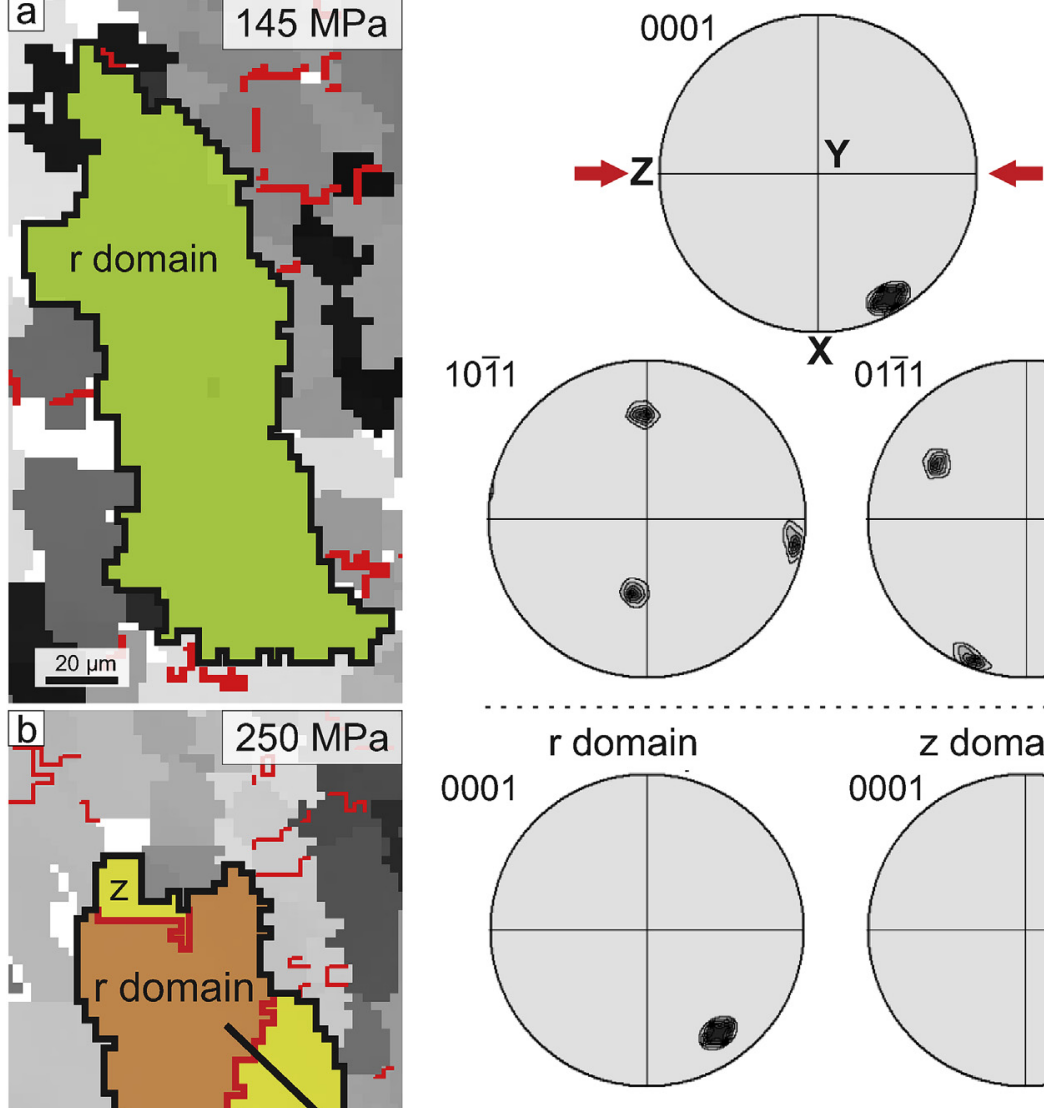

r domain

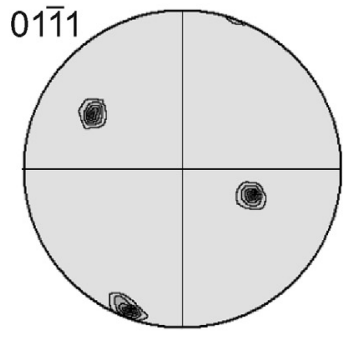

0001

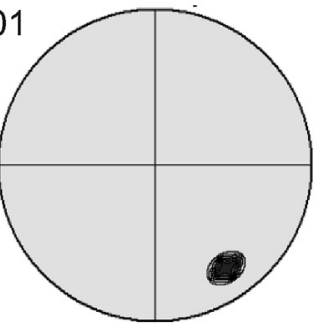

z domain

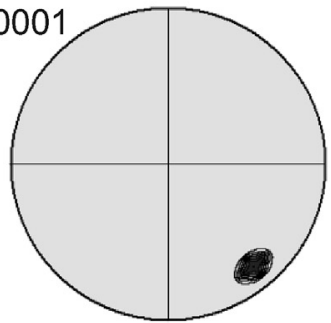

1011
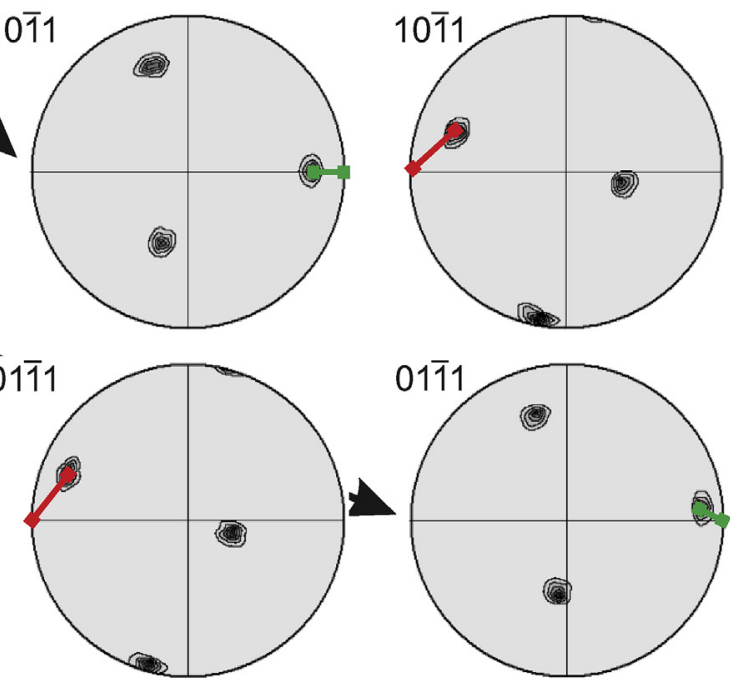

Fig. 6. EBSD orientation map of (a) a DTB-free single quartz grain of the sample stressed at $145 \mathrm{MPa}$ (highlighted in green) and (b) a DTB-containing single quartz grain of the sample stressed at $250 \mathrm{MPa}$, showing two different domains (highlighted in orange and yellow). Pole figures of c-axis, $r$ and $\mathrm{z}$ rhomb poles are shown for the different twin domains. Notice that for the DTB-free quartz grain one of the $r$ rhomb poles is close to the axial compressive stress direction (Z; red arrows). For the DTBcontaining grain, the green and red bars represent the shortest, respectively the longest distance from the closest $\mathrm{r}$ or $\mathrm{z}$ rhomb pole to the axial compressive stress direction $(\mathrm{Z})$. (For interpretation of the references to color in this figure legend, the reader is referred to the Web version of this article.) smoother, more regular and show fewer small submaxima. Nevertheless, the pole figures of the TOF and EBSD measurements are very similar, indicating that a statistically representative number of grains was measured by EBSD. This difference can be related to the total number of grains measured in the bulk orientation analysis. The rock volume measured by neutron diffraction is $\sim 1570 \mathrm{~mm}^{3}$ containing more than 1 million grains. The EBSD maps are between 1 and $5 \mathrm{~mm}^{2}$ large, containing only between 100 and 600 grains, thus several orders of magnitude less. Both the fewer number of grains and thus the increased influence of fabric heterogeneity makes that the EBSD pole figures are less regular than the TOF pole figures.

\subsection{Classification of quartz grains}

The EBSD analysis shows that quartz grains in the starting material, as well as in the experimentally stressed samples, contain DTBs. Most of the DTBs are straight or slightly curved and run through the whole quartz grain, while others are small (only a few pixels large) and form an irregular patchy pattern. We manually classified all grains into three types, (1) grains completely free of DTBs (Fig. 6a), (2) grains containing straight to curvy DTBs (Fig. 6b) and (3) grains containing patchy DTBs. Grains containing only a few single pixel-sized DTBs, as well as grains with less than $5 \%$ of twin domains, were considered as DTB-free grains.

We see in all scans grains of all three types. The number of measured grains depends on the area size of the EBSD scan and the analytical step size (Table 1). We analyzed between 22 and 94 grains per each EBSD 
Table 1

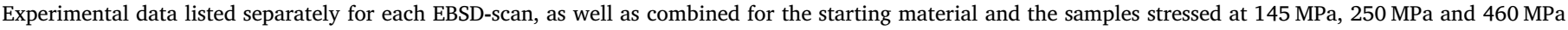
differential stress.

\begin{tabular}{|c|c|c|c|c|c|c|c|c|}
\hline EBSD scan & $\begin{array}{l}\text { Scan area } \\
\left(1000 \times \mu \mathrm{m}^{2}\right)\end{array}$ & $\begin{array}{l}\text { Step Size } \\
\left(\mathrm{mm}^{2}\right)\end{array}$ & $\begin{array}{l}\text { Non-analyzed } \\
\text { scan area (\%) }\end{array}$ & $\begin{array}{l}\text { Total number of } \\
\text { analyzed grains }\end{array}$ & $\begin{array}{l}\text { Number of DTB- } \\
\text { free grains }\end{array}$ & $\begin{array}{l}\text { Fraction of DTB- } \\
\text { free grains }(\%)\end{array}$ & $\begin{array}{l}\text { Number of DTB- } \\
\text { containing grains }\end{array}$ & $\begin{array}{l}\text { Fraction of DTB- } \\
\text { containing grains(\%) }\end{array}$ \\
\hline Starting & 5821 & & & 202 & 95 & 47.0 & 107 & 53.0 \\
\hline Br-undef-A & 1863 & 3.0 & $\sim 10$ & 73 & 28 & 38.4 & 45 & 61.6 \\
\hline Br-undef-B & 3532 & 3.5 & $\sim 10$ & 94 & 50 & 53.2 & 44 & 46.8 \\
\hline Br-undef-C & 426 & 2.5 & $\sim 15$ & 35 & 17 & 48.6 & 18 & 51.4 \\
\hline Br-145 MPa & 1147 & & & 88 & 40 & 45.5 & 48 & 54.5 \\
\hline Br-145-C & 421 & 2.5 & $\sim 15$ & 50 & 22 & 44.0 & 28 & 56.0 \\
\hline Br-145-E & 726 & 2.0 & $\sim 15$ & 38 & 18 & 47.4 & 20 & 52.6 \\
\hline Br-250 MPa & 2536 & & & 96 & 63 & 65.6 & 33 & 34.4 \\
\hline Br-250-A & 689 & 3.0 & $\sim 25$ & 31 & 21 & 67.7 & 10 & 32.3 \\
\hline Br-250-B & 777 & 5.0 & $\sim 35$ & 27 & 20 & 74.1 & 7 & 25.9 \\
\hline $\mathrm{Br}-250-\mathrm{C}$ & 1070 & 5.0 & $\sim 30$ & 38 & 22 & 57.9 & 16 & 42.1 \\
\hline $\mathrm{Br}-460 \mathrm{MPa}$ & 2330 & & & 129 & 65 & 50.4 & 64 & 49.6 \\
\hline Br-460-A & 712 & 2.5 & $\sim 25$ & 42 & 18 & 42.9 & 24 & 57.1 \\
\hline $\mathrm{Br}-460-\mathrm{B}$ & 670 & 2.5 & $\sim 30$ & 37 & 20 & 54.1 & 17 & 45.9 \\
\hline Br-460-C & 261 & 2.5 & $\sim 20$ & 22 & 12 & 54.5 & 10 & 45.5 \\
\hline Br-460-D & 687 & 2.5 & $\sim 40$ & 28 & 15 & 53.6 & 13 & 46.4 \\
\hline
\end{tabular}

scan, resulting in a total number of 202 grains for the starting material and between 88 and 129 for each of the stressed samples. All scans contain patchy DTB-containing grains and very small grains with only a few measurement points (less than 5). Due to their incompleteness, grains at the edge of the scan cannot be classified as DTB-free or DTBcontaining. These grains, as well as very small grains and all patchy DTB-containing grains are not taken into account for the SGOA. On average, around $20 \%$ of the measured scan area is subsequently excluded for the SGOA (Table 1).

In the starting material around $47 \%$ of the analyzed grains are free of DTBs. The stressed samples have similar or slightly higher percentages of DTB-free grains, $\sim 46 \%$ (145 MPa), $\sim 66 \%$ (250 MPa) and $\sim 50 \%$ (460 MPa) (Table 1).

We counted the number of DTB-free or DTB-containing grains disregarding their size. Thus, large grains and small grains have the same weight in the analysis. In scans with a large scan area (e.g. Br-starting-A \& B; Table 1) we have fewer measuring points per grain (analytical step size $5 \mu \mathrm{m}$ ), whereas in scans with smaller scan area (analytical step size $2-3 \mu \mathrm{m})$, which is the case for most of the stressed samples, we have more measuring points per grain. Disregarding this difference in number of measuring points per grain may have a minor impact on the accuracy of the results of the analysis.

\subsection{Single grain orientation analysis}

The SGOA builds on the classification of the quartz grains according to the presence of DTBs. Our basic assumption is that DTB-free grains are either crystallographically in a stable orientation, i.e. a crystallographic orientation with an $\mathrm{r}$ rhomb pole parallel to the axial compressive stress direction, or completely twinned, i.e. with an original (prior to twinning) crystallographic orientation with a $\mathrm{z}$ rhomb pole parallel to the axial compressive stress direction (Fig. 7). DTB-containing grains, on the other hand, are considered being in an intermediate crystallographic orientation hampering complete Dauphiné twinning.

Subsequently a manual orientation analysis has been performed of both the DTB-free and DTB-containing grains. On the one hand, DTBfree grains were first selected manually and their crystallographic orientation $(\langle 0001\rangle,\{10 \overline{1} 1\}$ and $\{01 \overline{1} 1\})$ was recorded. We see that in DTB-free grains the crystallographic orientation distribution of the $r$ rhomb poles is indeed such that one of the $r$ rhomb maxima is parallel to the axial compressive stress direction (Fig. 6a).

In the DTB-containing grains, DTBs separate twin domains. Because the twin and the host cannot be discerned, we label the twin domains $\mathrm{r}$ domains (i.e. so-called twin) and z-domains (i.e. so-called host). The distinction is based on the orientation distribution of the $\mathrm{r}$ rhomb and $\mathrm{z}$ rhomb poles with respect to the axial compressive stress direction (Fig. 6b). In the r-domains the $\mathrm{r}$ rhomb pole is closer to the axial compressive stress direction than the $\mathrm{z}$ rhomb pole and vice versa for the $\mathrm{z}$-domain.

This procedure was applied on all EBSD-scans, as illustrated in Fig. 8. This figure does not show all of the EBSD-scans, but more data are included in Table 1. We see DTB-free and DTB-containing grains in both the starting material and the three stressed samples. All DTB-free grains are colored in green, whereas the DTB-containing grains are shown in orange (r-domains) and yellow (z-domains). The area that was not used for the SGOA is shown in grey (Fig. 8). Remarkably, we see that in DTB-containing grains $r$-domains in neighboring grains are seemingly juxtaposed (Fig. 8).

\subsection{Pole figure analysis in DTB-free and DTB-containing grains}

In a further step the crystallographic orientation distribution of the different type of grains in the different samples was combined in distinct pole figures, for DTB-free grains (Fig. 9) and for DTB-containing grains (Fig. 10). For DTB-free grains we used three pole figures, for the DTB-containing grains, we used five pole figures for each sample.

\subsubsection{DTB-free grains}

We see a clear difference between the starting material and the stressed samples. For the starting material (total scan area: $5.82 \mathrm{~mm}^{2}$ ) a total amount of 95 DTB-free grains have been measured (Table 1). There is a $\mathrm{r}$ rhomb maximum about $10^{\circ}$ away from the X-direction with a slightly developed girdle distribution orthogonal to the maximum. The maximum preferred orientation, close to the X-direction, is relatively strong $(\sim 17 \mathrm{mrd})$. The pole figure of the $\mathrm{z}$ rhombs shows an exactly opposite orientation distribution. The $r$ rhomb maxima correlate with the $\mathrm{z}$ rhomb minima and vice versa (Fig. 9a).

The sample stressed at $145 \mathrm{MPa}$ (total scan area: $1.15 \mathrm{~mm}^{2}$ ) contains 40 DTB-free grains. The CPO has been completely changed for both $r$ and $\mathrm{z}$ rhombs. The $\mathrm{r}$ rhombs show a broad maximum $(\sim 8 \mathrm{mrd})$ close to the Z-direction with a girdle containing two small submaxima perpendicular to it (Fig. 9b). The $\mathrm{z}$ rhombs show three maxima which correlate with the $\mathrm{r}$ rhomb minima. The maximum preferred orientation for $\mathrm{z}$ rhombs is $\sim 10 \mathrm{mrd}$.

In the sample stressed at $250 \mathrm{MPa}$ (total scan area: $2.54 \mathrm{~mm}^{2}$ ) 63 DTB-free grains have been measured. The orientation distribution of the rhombs look similar to the sample stressed at $145 \mathrm{MPa}$, but the $\mathrm{r}$ rhomb maximum close to the Z-direction is much stronger ( $\sim 24 \mathrm{mrd})$ and more distinct. The girdle orthogonal to the Z-direction contains two 


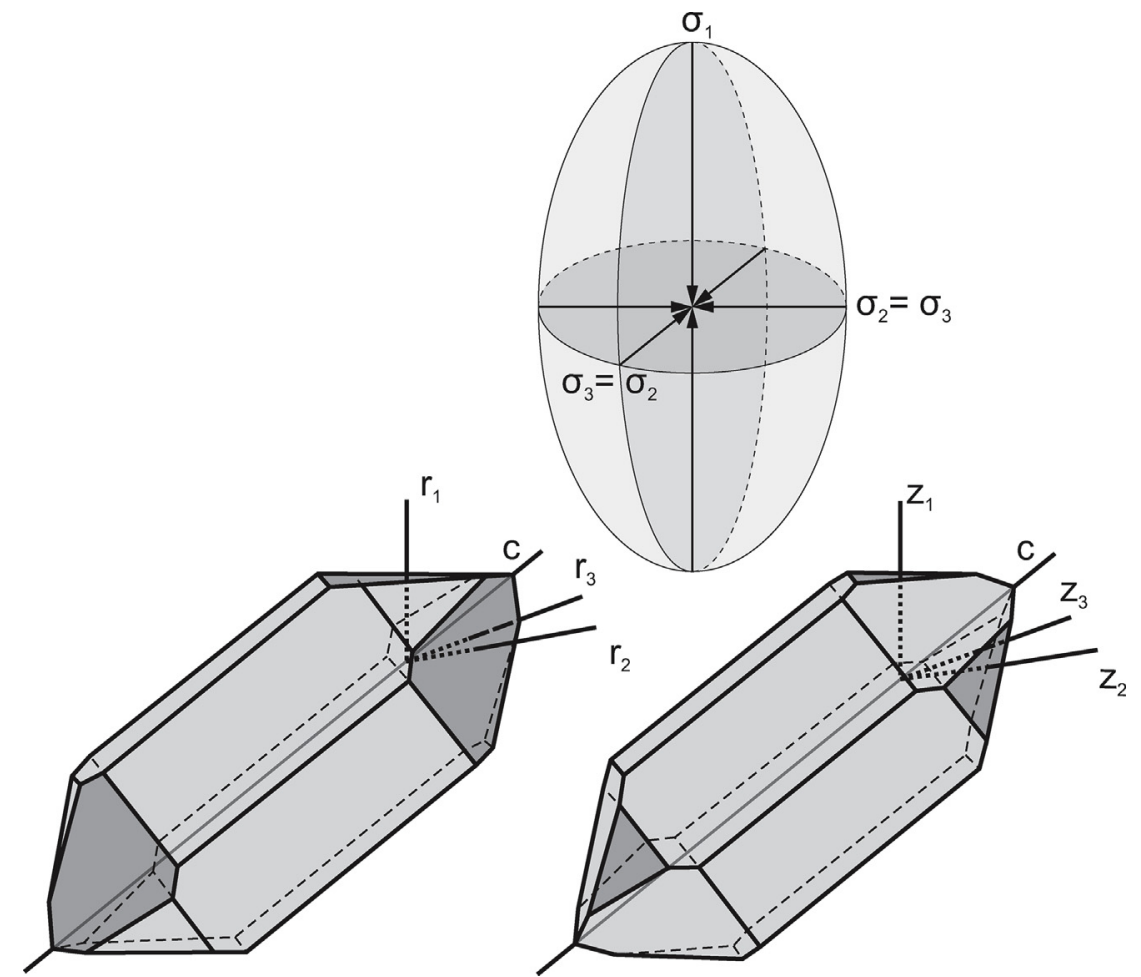

Fig. 7. Optimum crystallographic orientation of a quartz crystal with respect to the maximum principal stress direction $\left(\sigma_{1}\right)$ for DTB-free quartz grains, either with an $r$ rhomb pole parallel to the maximum principal stress direction (left), or with a $\mathrm{z}$ rhomb pole parallel to the maximum principal stress direction (right). Notice the orientation of both other rhomb poles, at approximately $90^{\circ}$ of the maximum principal stress direction, as well as the orientation of the c-axis, at $52^{\circ}$ of the principal stress direction. submaxima. The $\mathrm{z}$ rhomb maxima correlate again with the $\mathrm{r}$ rhomb minima (Fig. 9c). The maximum preferred orientation for $\mathrm{z}$ rhombs is $\sim 24$ mrd.

The sample stressed at $460 \mathrm{MPa}$ (total scan area: $2.33 \mathrm{~mm}^{2}$ ) contains 65 DTB-free grains (Fig. 9d). The $r$ rhombs show a broad maximum close to the Z-direction with a girdle orthogonal to the maximum. The girdle contains two small submaxima, which are much less developed than the submaxima of the girdle of the samples stressed at $145 \mathrm{MPa}$ and $250 \mathrm{MPa}$. The maximum preferred orientation for $r$ rhombs is $\sim 26$ mrd and for $\mathrm{z}$ rhombs $\sim 25$ mrd.

The c-axis orientation distribution still shows the girdle pattern similar as in the case of the bulk orientation analysis, but the c-axis orientation distribution shows a more distinct maximum, probably due to the big difference in the amount of analyzed grains between the bulk orientation pole figures and the SGOA-pole figures.

\subsubsection{DTB-containing grains}

The orientation distribution of the DTB-containing grains for the different samples is shown in Fig. 10. For the SGOA, we take the orientation distribution of all $\mathrm{r}$-domains and all z-domains separately and show for each twin domain the orientation distribution of both $\mathrm{r}$ and $\mathrm{z}$ rhombs. It can be noted that $\mathrm{r}$ rhomb pole figures in $\mathrm{r}$ domains are identical to the $\mathrm{z}$ rhomb pole figures in $\mathrm{z}$ domains, and vice versa (Fig. 10)

Again we see a clear difference between the starting material and the stressed samples. The starting material contains 107 measured DTBcontaining grains. For the r-domains, there is a $\mathrm{r}$ rhomb maximum ( $\sim 19 \mathrm{mrd}$ ) which is about $15^{\circ}$ clockwise away from the X-direction with a girdle distribution orthogonal to the maximum, containing two submaxima. The $\mathrm{r}$ rhomb maxima correlate with the $\mathrm{z}$ rhomb minima and vice versa (Fig. 10a). The maximum preferred orientation for $\mathrm{z}$ rhombs is $\sim 14 \mathrm{mrd}$.

The sample stressed at $145 \mathrm{MPa}$ contains 48 DTB-containing grains. The $\mathrm{r}$ rhombs show a maximum $(\sim 10 \mathrm{mrd})$ close to the Z-direction $\left(10^{\circ}\right.$ towards $\mathrm{Y}$ ) and two small submaxima near the $\mathrm{Y}$ - and $\mathrm{X}$-direction (Fig. 10b). The $\mathrm{z}$ rhombs show three maxima which correlate the $\mathrm{r}$ rhomb minima. The maximum preferred orientation for $\mathrm{z}$ rhombs is $\sim 8$ mrd.

In the sample stressed at $250 \mathrm{MPa}, 33 \mathrm{DTB}$-containing grains have been measured. The $r$ rhomb maximum $(\sim 12 \mathrm{mrd})$ is $20^{\circ}$ away from the Z-direction (towards Y). In between we see a girdle orthogonal to the Z-direction containing a maximum near the X-direction. The $\mathrm{Z}$ rhombs show a partial girdle with three maxima (Fig. 10c). The maximum preferred orientation for $\mathrm{z}$ rhombs is $\sim 9 \mathrm{mrd}$.

The sample stressed at $460 \mathrm{MPa}$ contains $64 \mathrm{DTB}-$ containing grains (Fig. 10d). The $\mathrm{r}$ rhombs show a maximum ( $\sim 22 \mathrm{mrd})$ close the Zdirection $\left(10^{\circ}\right.$ towards $\left.\mathrm{Y}\right)$ with a girdle orthogonal to the maximum. The girdle contains two small submaxima, which are much stronger developed than the submaxima of the samples stressed at $145 \mathrm{MPa}$ and $250 \mathrm{MPa}$. The maximum preferred orientation for $\mathrm{r}$ rhombs is $\sim 22 \mathrm{mrd}$ and for $\mathrm{z}$ rhombs $\sim 18 \mathrm{mrd}$.

Looking at the z-domains, we see that the preferred orientation of the $\mathrm{r}$ rhomb and $\mathrm{z}$ rhomb poles switch. For the $\mathrm{z}$-domains, the $\mathrm{z}$ rhomb pole figures are very similar to the $r$ rhomb pole figures of the $r$-domains; and vice versa (Fig. 10).

The c-axis orientation distribution also deviates from the girdle pattern as seen in the bulk orientation analysis (Fig. 5), but less than in the case of the DTB-free grains (Fig. 9). This suggests that in the case of DTB-containing grains a population of grains with a wider range in caxis orientation is sampled than in the case of DTB-free grains. Again, the c-axis orientation of the starting material is different from the c-axis orientation in the different stressed samples, again suggesting that a different orientation population of quartz grains is sampled in the SGOA.

\section{Interpretation}

\subsection{Bulk orientation analysis}

The bulk orientation analysis as illustrated in Fig. 5 shows a decrease in the concentration of $\mathrm{z}$ rhomb poles and an increase in the concentration of $r$ rhomb poles parallel to the applied axial compressive stress direction, while maintaining the c-axis orientation distribution. This can be interpreted as an activation of mechanical Dauphiné 

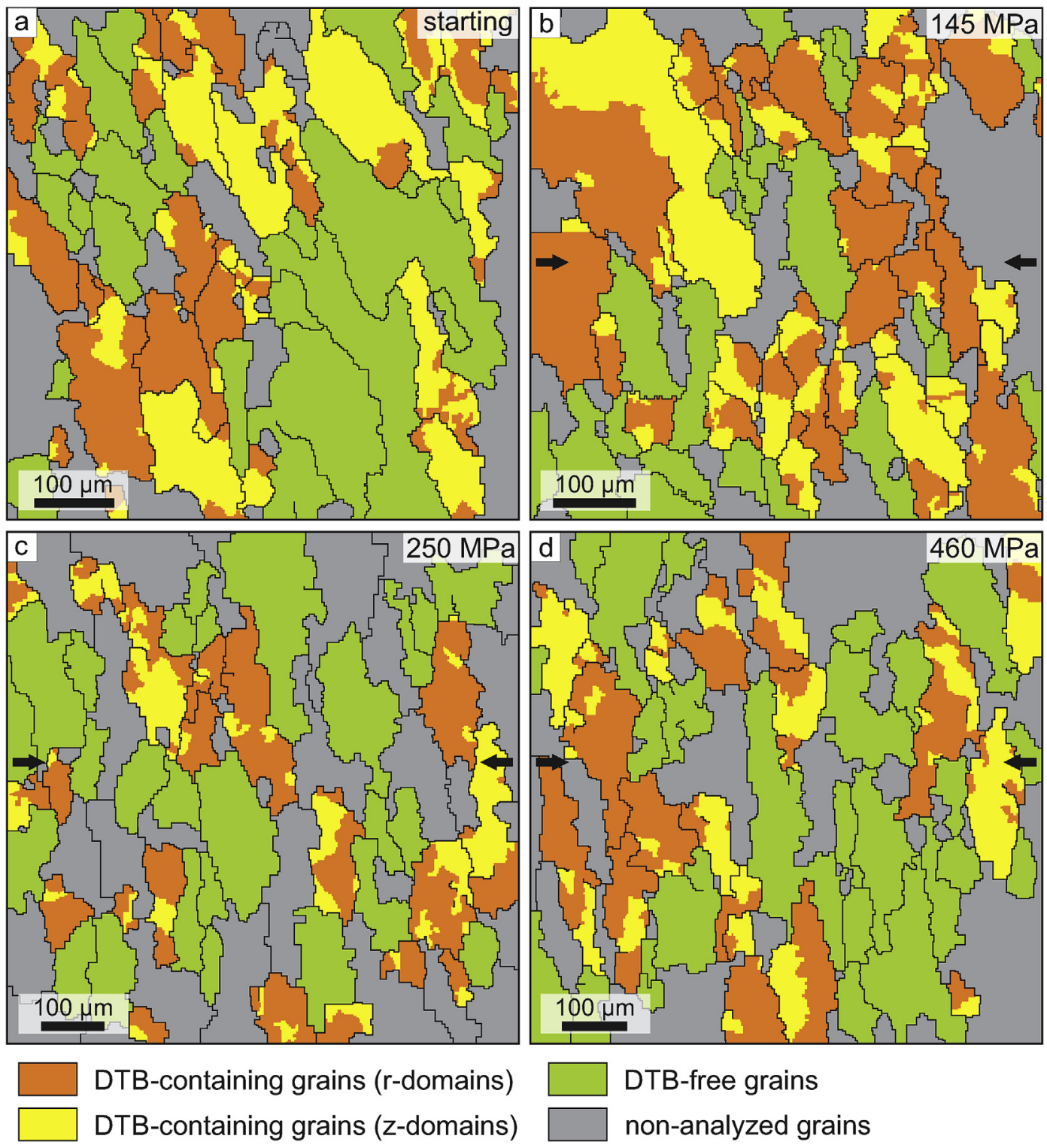

DTB-free grains

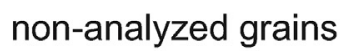

Fig. 8. Processed EBSD-OIM orientation maps of (a) starting material; (b) sample stressed at $145 \mathrm{MPa}$; (c) sample stressed at $250 \mathrm{MPa}$; (d) sample stressed at $460 \mathrm{MPa}$. DTB-free grains are shown in green; DTB-containing grains in orange (r-domains) and yellow (z-domains); and grains that were not taken into account for the SGOA are shown in grey. High-angle grain boundaries are shown in black. The axial compressive stress direction is indicated by black arrows (horizontal). (For interpretation of the references to color in this figure legend, the reader is referred to the Web version of this article.)

twinning due to applied axial compressive stress. The consistency of the c-axis orientation distribution in all samples and the almost negligible amount of inelastic deformation during the compression experiments, moreover, infers that no significant dislocation plasticity occurred during the experiments.

The $r$ rhomb maximum parallel to the axial compressive stress direction of the sample stressed at $250 \mathrm{MPa}$ shows only a slight increase compared to the sample stressed at $145 \mathrm{MPa}$. The difference between the samples stressed at $250 \mathrm{MPa}$ and $460 \mathrm{MPa}$ is even smaller. Thus most grains with a high tendency for twinning have seemingly already undergone Dauphiné twinning at a differential stress of $145 \mathrm{MPa}$ and higher differential stresses do not substantially activate additional twinning in more grains. Previous in situ neutron diffraction compression experiment studies showed similar results, suggesting that Dauphiné twinning in polycrystalline quartz rocks initiates at stresses less than $50 \mathrm{MPa}$ and saturates at $400 \mathrm{MPa}$ at $500{ }^{\circ} \mathrm{C}$ (Wenk et al., 2005, 2006).

\subsection{Classification of quartz grains}

The EBSD analysis shows that the starting material and the stressed samples contain DTBs (Fig. 8). The shape of DTBs looks similar in all scans. We compared the ratio of DTB-free grains relatively to DTBcontaining grains to figure out if we can see a difference between the different experimentally stressed samples.

We can see a slight trend from the starting material, over the sample stressed at $145 \mathrm{MPa}$ to the samples stressed at $250 \mathrm{MPa}$ and $460 \mathrm{MPa}$ (Table 1). The ratio of DTB-free grains to DTB-containing grains increases with higher differential stress. This increase may suggest that increasing differential stress may still lead to further completion of Dauphiné twinning in some grains. It can, though, not be excluded that this small difference is entirely due to fabric heterogeneity between the stressed samples. 


\section{DTB free}

\section{a starting material}
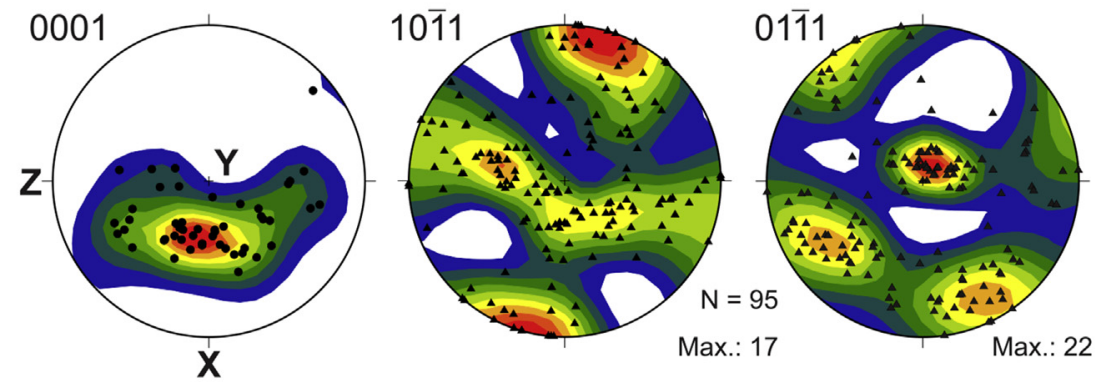

b $145 \mathrm{MPa}$
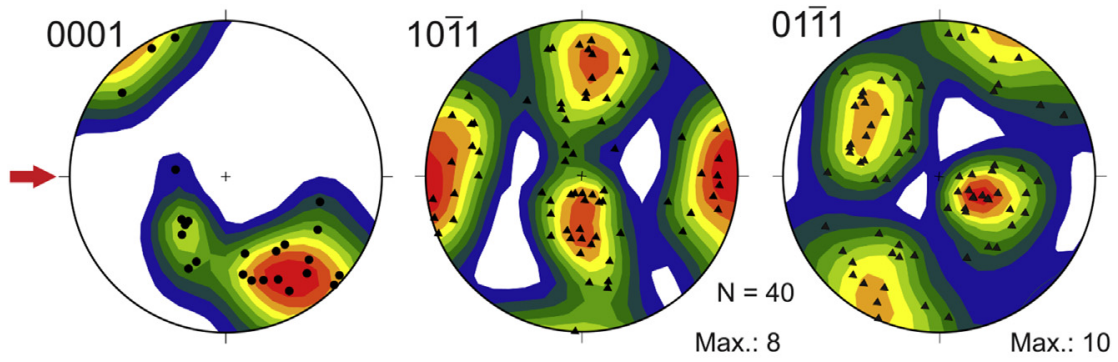

C $250 \mathrm{MPa}$
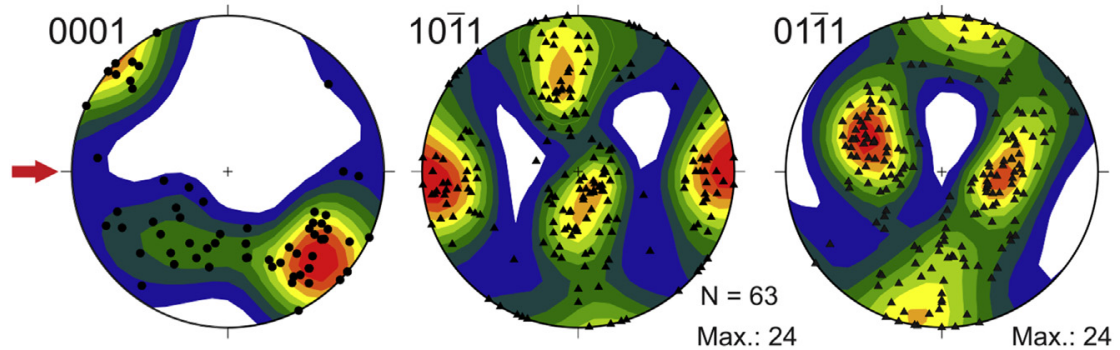

\section{d $460 \mathrm{MPa}$}
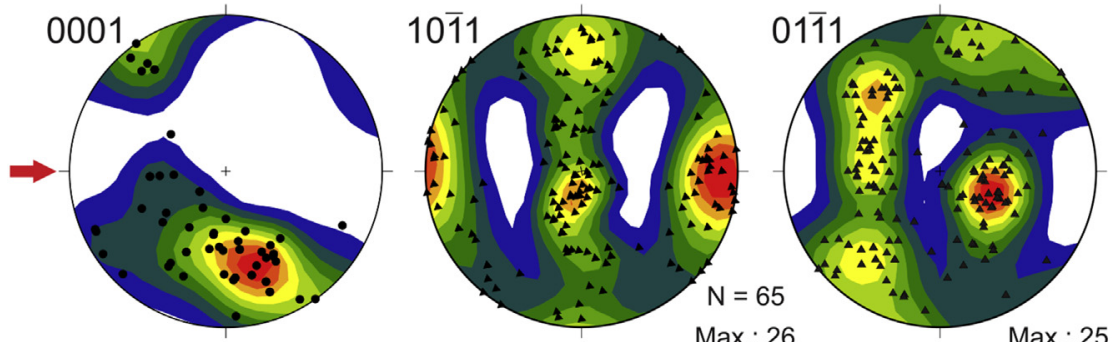

Fig. 9. Single grain orientation distribution of positive (left) and negative (right) rhombs in DTB-free grains. (a) Starting material; (b) sample stressed at $145 \mathrm{MPa}$; (c) sample stressed at $250 \mathrm{MPa}$; (d) sample stressed at $460 \mathrm{MPa}$. The axial compressive stress direction in all stressed samples is horizontal (parallel to Z, red arrow). Equal area, upper hemisphere projection. (For interpretation of the references to color in this figure legend, the reader is referred to the Web version of this article.)

\subsection{Single grain orientation analysis}

The SGOA can give valuable additional information about the changes occurring during the axial compression experiments, which is not available in a bulk orientation analysis. It enables to distinguish between grains with an optimum orientation for complete Dauphiné twinning (Fig. 7) and grains with a less favorable orientation for complete twinning. The former grains are eventually free of DTBs (Fig. 9), while the latter grains still contain DTBs (Fig. 10).

\subsubsection{DTB-free grains}

Fig. 9 shows for all stressed samples an increase of the number of $r$ rhomb poles and a decrease of the number of $\mathrm{z}$ rhomb poles for DTBfree grains in the axial compressive stress direction, compared to the starting material (Fig. 9a). Thus, grains with $r$ rhombs orthogonal to the axial compressive stress direction were either already in a stable orientation to start with or were twinned completely towards the stable orientation during axial compression (Fig. 7). We have already seen a similar effect in the bulk orientation analysis (Fig. 5). Nevertheless, the pole figures are more clear with distinct maxima and girdles because only DTB-free grains were considered. These DTB-free grains can all be 


\section{a starting material}

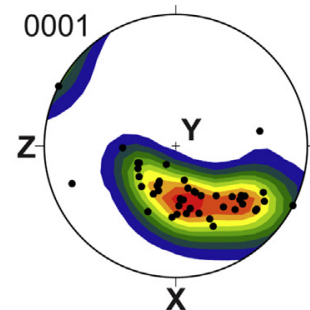

b $145 \mathrm{MPa}$

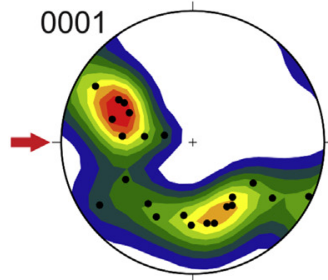

C $250 \mathrm{MPa}$

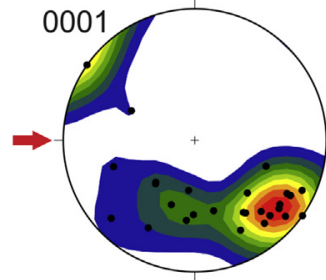

d $460 \mathrm{MPa}$

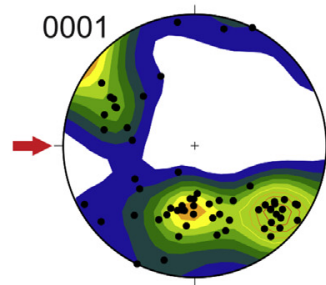

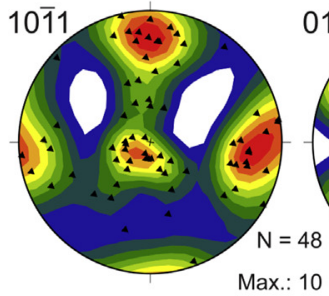
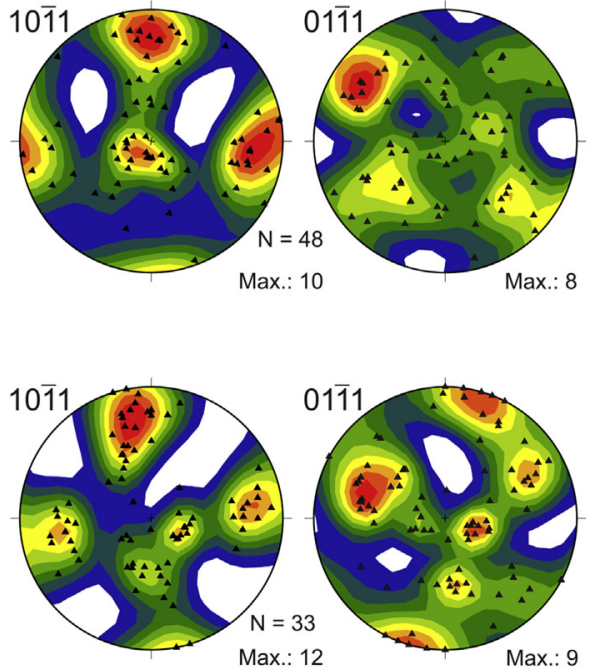

r domain

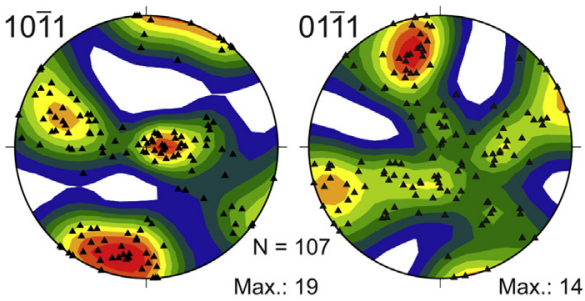

Max.: 12

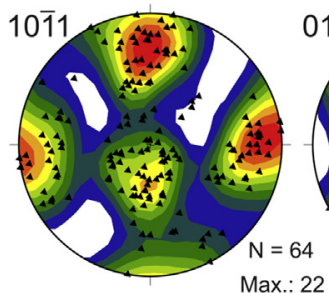

\section{DTB containing}

\section{z domain}
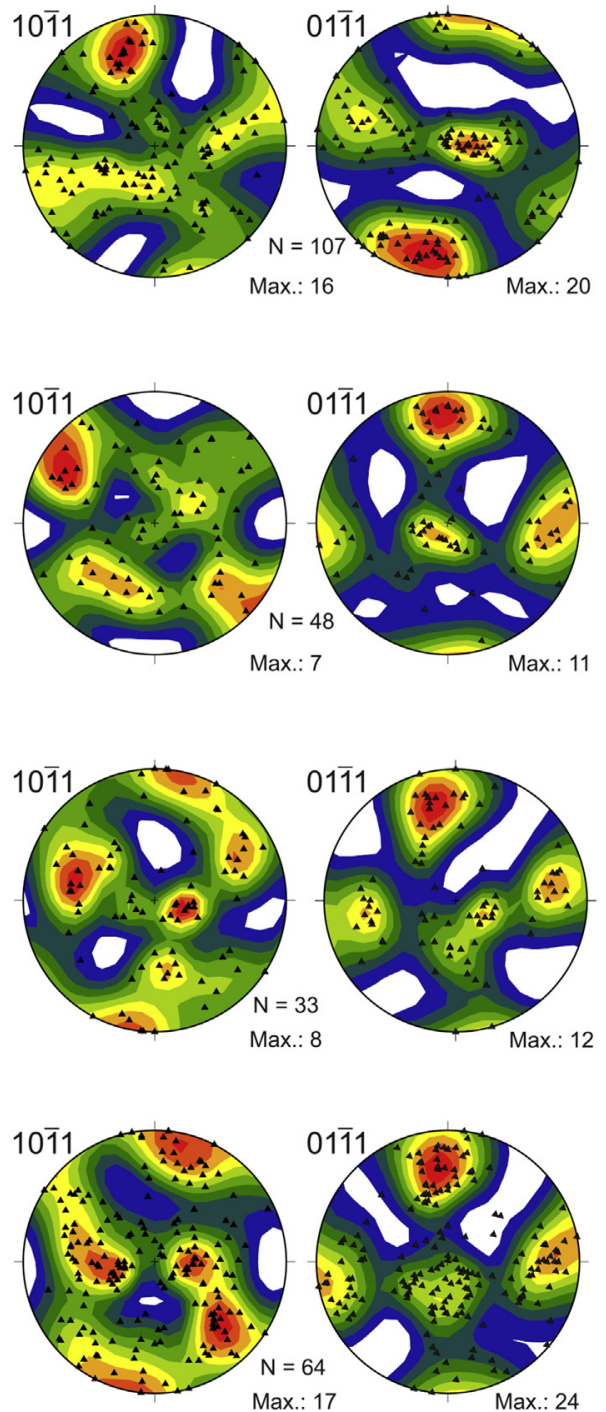

Max: 17

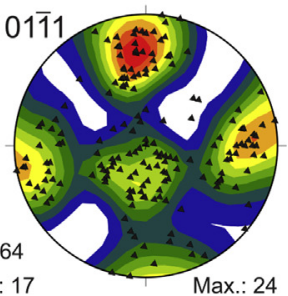

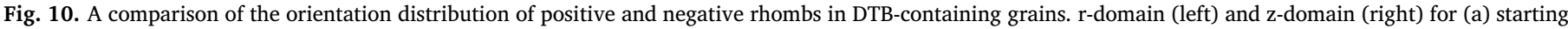

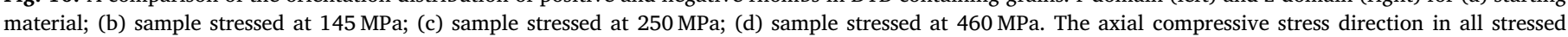

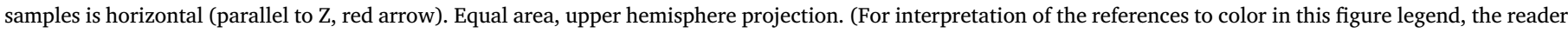
is referred to the Web version of this article.)

considered single grain r-domains (Fig. 6).

The orientation difference in the pattern of the three stressed samples is relatively small, suggesting that a differential stress of $145 \mathrm{MPa}$ is sufficient to approach complete mechanical Dauphiné twinning. It seems that the initiation of Dauphiné twinning starts below $145 \mathrm{MPa}$ differential stress. Nevertheless, the preferred orientation for the $r$ rhomb poles increases still slightly from $145 \mathrm{MPa}$ to $250 \mathrm{MPa}$. The analysis of the samples stressed at $250 \mathrm{MPa}$ include more measured DTB-free grains (Table 1), which could lead to a more distinct maximum. We cannot see much difference between the sample stressed at $250 \mathrm{MPa}$ and the sample stressed at $460 \mathrm{MPa}$, so twinning is probably already saturated around $250 \mathrm{MPa}$ and further increase of applied axial compressive stress does no longer have a significant impact.

\subsubsection{DTB-containing grains}

Fig. 10 shows for the starting material and all stressed samples a comparison of the orientation distributions between the $\mathrm{r}$ - and the $\mathrm{z}$ domains. In principle, the c-axis orientation distribution should be the same for both $r$-domains and z-domains. This implies that the $r$ rhomb poles in the $\mathrm{r}$-domain correspond to the $\mathrm{z}$ rhomb poles in the $\mathrm{z}$-domain and vice versa. Indeed the c-axis orientation distribution of both domains is very similar, nevertheless there are small differences in orientation on both sides of a DTB. The reasons for these differences could be measurement inaccuracies or a difference in the elastic properties of both domains. For example, the z-domain could deform more easily comparing with the r-domain (e.g. Menegon et al., 2011).

The $r$ rhomb orientation distribution of the DTB-containing grains is similar as for the DTB-free grains close to the axial compressive stress direction, except for the sample stressed at $145 \mathrm{MPa}$, where the maxima are around $20^{\circ}$ away from the Z-direction. Also the girdle perpendicular to the axial compressive stress direction is less distinct (Fig. 10b).

This intermediate orientation is seemingly less sensitive to complete Dauphiné twinning. Therefore, these DTB-containing grains are considered not really appropriate to be used as a tool to estimate the orientation of the axial compressive stress direction. 


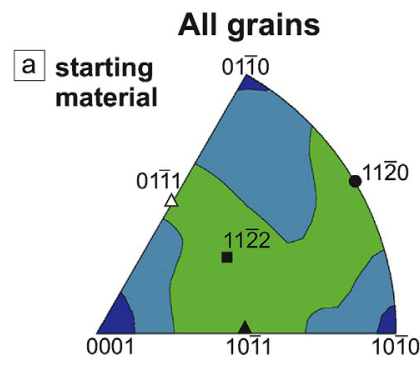

\section{DTB-free grains}

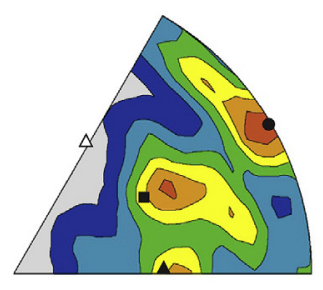

b $145 \mathrm{MPa}$

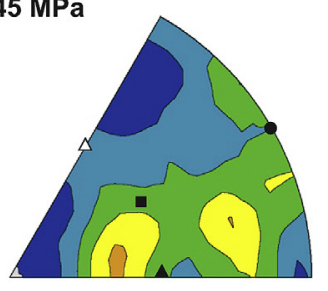

C $250 \mathrm{MPa}$

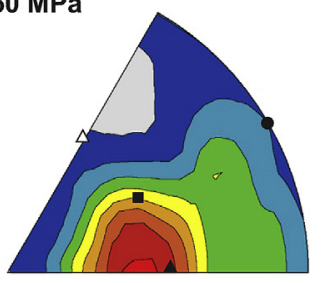

d $460 \mathrm{MPa}$

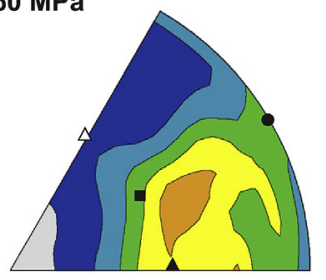

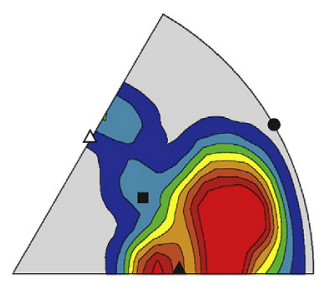
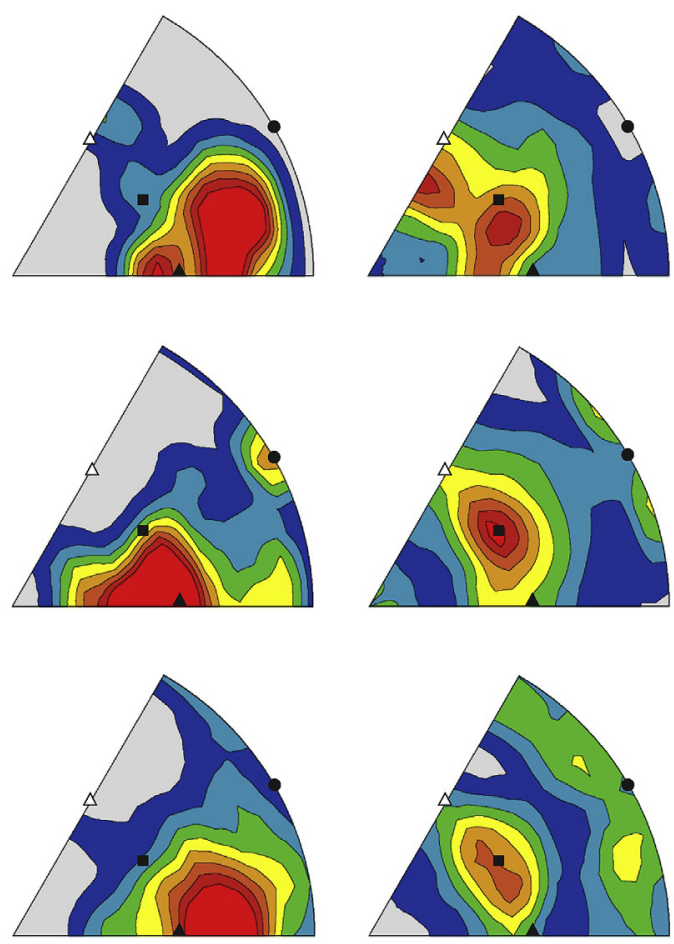

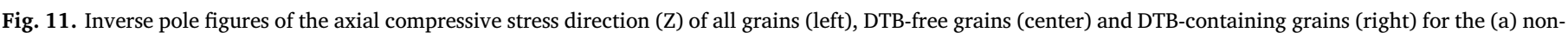

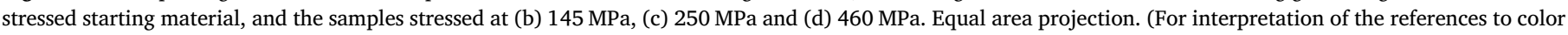
in this figure legend, the reader is referred to the Web version of this article.)

\subsection{Inverse pole figures}

After discussing pole figures, we now discuss inverse pole figures of the axial compressive stress direction ( $\mathrm{Z}$ ) in the experimentally deformed samples. The inverse pole figure for quartz (Laue group $3 \mathrm{~m}$ ) can be represented in the asymmetric unit sector 0001-1010-011̄0. In case of the starting material the inverse pole figure presents the orientation distribution of the pole to the foliation (Z-axis in Fig. 4). Besides the bulk inverse pole figures (Fig. 11, left column), we also present inverse pole figures based on the SGOA of DTB-free (Fig. 11, center) and DTB-containing grains (Fig. 11, right column). The bulk inverse pole figures are based on the EBSD scans (Fig. 5, left column). The inverse pole figures for DTB-free and DTB-containing grains are based on manually selected grains, irrespective of their size (one orientation per grain) as was done for pole figures (Figs. 9 and 10).

\subsubsection{Bulk orientation distribution}

The bulk orientation distribution for the starting material is weak and very irregular (Fig. 11a, left column). For the stressed samples a maximum near $\{10 \overline{1} 1\}$ as well as a minimum near $\{01 \overline{1} 1\}$ is observed. A comparison of the patterns of the starting material and the stressed samples thus clearly indicates that twinning has occurred. Already at $145 \mathrm{MPa}$ a maximum (1.8 mrd) is present close to $\{10 \overline{1} 1\}$ (Fig. $11 \mathrm{~b}$, left column). This pattern is most regular for $250 \mathrm{MPa}$ with a distinct maximum (3 mrd) near $\{10 \overline{1} 1\}$ (Fig. 11c, left column). The maximum at
$460 \mathrm{MPa}$ is weaker (1.8 mrd) (Fig. 11d, left column), most probably due to fabric heterogeneities or counting statistics.

\subsubsection{DTB-free grains}

In the case of the DTB-free grains, the starting material shows an irregular pattern with several small maxima at $\{10 \overline{1} 1\},\{11 \overline{2} 2\}$ and $\{11 \overline{2} 0\}$ (Fig. 11a, center). In the case of the $145 \mathrm{MPa}$ (Fig. 11b, center) sample, we see a strong maximum as well as a smaller maximum on both sides of $\{10 \overline{1} 1\}$, while for the sample stressed at $250 \mathrm{MPa}$ (Fig. 11c, center), we see one main maximum around $\{10 \overline{1} 1\}$ and a small sub maximum around $\{11 \overline{2} 0\}$. The sample stressed at $460 \mathrm{MPa}$ has only one maximum close to $\{10 \overline{1} 1\}$ (Fig. 11d, center). The differences between the stressed samples are again most probably due to fabric heterogeneities and the relatively few measured grains for the $145 \mathrm{MPa}$ sample.

\subsubsection{DTB-containing grains}

For the DTB-containing grains of the starting material, we see maxima close to $\{10 \overline{1} 1\},\{01 \overline{1} 1\}$ and $\{11 \overline{2} 0\}$ (Fig. 11a, right column), indicating that a different orientation population of grains is sampled with respect to the DTB-free grains. For all the stressed samples the maximum is near $\{11 \overline{2} 2\}$, an orientation for which there is no real incentive to twin (Fig. 11b-d, right column). While grains with an orientation near $\{01 \overline{1} 1\}$ had a tendency to undergo Dauphiné twinning, grains in an intermediate orientation remained largely unchanged. 
Again for the samples stressed at $250 \mathrm{MPa}$ and $460 \mathrm{MPa}$ the maximum remains intermediate between positive and negative rhombs and becomes even more pronounced. This is probably also due to the higher number of measured grains.

\section{Discussion}

The bulk orientation distribution analysis, using both EBSD and TOF neutron diffraction, reveals similar results as previous studies on polycrystalline quartz materials, described by various authors (e.g. Tullis, 1970; Tullis and Tullis, 1972; Wenk et al., 2006). Those studies only consider the bulk orientation distribution of quartz, which indirectly inferred Dauphiné twinning based on early simple stress experiments on quartz single crystals (Schubnikov and Zinserling, 1932; Thomas and Wooster, 1951). As an addition to the bulk orientation analysis, we introduced a novel SGOA. The classification of DTB-free and DTB-containing grains and the manual selection and processing of the crystallographic orientation distribution of the quartz grains reveals that the DTB-free grains are most appropriate to reconstruct the axial compressive stress direction in these experimentally stressed samples. Contrary, the DTB-containing grains seem to provide an ambiguous result with respect to the axial compressive stress direction. Most DTBcontaining grains appear to be in a $\{11 \overline{2} 2\}$ orientation (Fig. 11, right column), insensitive to twinning. DTB-free grains are either in a stable $\{10 \overline{1} 1\}$ orientation perpendicular to the axial compressive stress direction or were completely twinned because they originally were in a $\{01 \overline{1} 1\}$ orientation perpendicular to the axial compressive stress direction (Fig. 7).

The orientation distribution of the $r$ rhombs in the DTB-free grains thus clearly show a strong preferred orientation parallel to the axial compressive stress direction. In these axial compression experiments with a constant confining pressure of $300 \mathrm{MPa}$, the axial compressive stress direction corresponds to the maximum principal stress direction $\left(\sigma_{1}\right)$ (Fig. 7). By definition, the intermediate $\left(\sigma_{2}\right)$ and minimum $\left(\sigma_{3}\right)$ principal stress directions are perpendicular to the maximum principal stress direction $\left(\sigma_{1}\right)$ (Fig. 7). In case of an axial symmetrical stress state, no distinction can however be made between both principal stress directions $\left(\sigma_{2}=\sigma_{3}\right)$.

The angle between the poles to the three $r$ rhombs is $86^{\circ}$, approximating $90^{\circ}$. This particular angular relationship infers that if one of the three $r$ rhomb poles is parallel to the maximum principal stress direction $\left(\sigma_{1}\right)$, the two other $r$ rhomb poles are approximately oriented in the principal stress plane $\left(\sigma_{2} \sigma_{3}\right)$ (left on Fig. 7). The same angular relationship applies to the $\mathrm{z}$ rhomb poles, prior to Dauphiné twinning (right on Fig. 7).

In an axial compression experiment, with no difference between the intermediate and minimum principal stress, we would expect a perfect girdle orientation distribution of $r$ rhomb poles, orthogonal to the $r$ rhomb pole maximum parallel to the maximum principal stress direction. In the orientation distribution of the DTB-free grains (Fig. 9), we see clear $r$ rhomb submaxima within the girdle, suggesting a preferred orientation of the two other $r$ rhombs. At this stage, we can only assume that this particular preferred orientation is inherited from the pre-existing fabric. In this respect, it would be interesting to see how the $r$ rhomb orientation distribution would develop in a triaxial compression experiment.

We also have to keep in mind that ex situ experiments only show the final state of the compression experiment. In situ neutron diffraction experiments have shown, though, that some twinning reverts when stress is released (Wenk et al., 2007). Thomas and Wooster (1951) also showed that Dauphiné twins can be removed by maximizing elastic strain.

The axial compression experiments show that the initiation of Dauphiné twinning starts below $145 \mathrm{MPa}$ differential stress at $500{ }^{\circ} \mathrm{C}$ with a confining pressure of $300 \mathrm{MPa}$, and saturates between $250 \mathrm{MPa}$ and $460 \mathrm{MPa}$ differential stress. Other studies already showed that the parameters controlling mechanical Dauphiné twinning are primarily stress and temperature (Tullis and Tullis, 1972; Wenk et al., 2006), while confining pressure is of minor importance (Wenk et al., 2006). In general, experiments at ambient pressure (Thomas and Wooster, 1951) show similar results as experiments at $400 \mathrm{MPa}$ confining pressure (Tullis and Tullis, 1972). Also the mobility of twin boundaries, and thus the rate of twinning, affects initiation of Dauphiné twinning. Barber and Wenk (1991) described that DTBs are very mobile at higher temperatures ( $>300^{\circ} \mathrm{C}$ ), especially near the $\alpha-\beta$ transition temperature, while the twins are small. At low temperatures, on the other hand, they suggest that DTBs are locked onto dislocation or other crystal defects or microstructures. It is likely that subgrain boundaries $\left(2-10^{\circ}\right)$ in both DTB-free and DTB-containing grains could have a similar influence (e.g. Menegon et al., 2011). Some authors have also reported that DTBs are localized along crystal defects and fluid inclusions (e.g. Frondel, 1962; Fall et al., 2016). In further studies, we have to focus on the characteristics of the DTBs and their relationship with the microstructure, especially the grain and subgrain boundaries.

No significant effect is expected due to the homogeneous grain size distribution of the quartzite studied. Our compression experiments give very similar results as experiments on fine-grained Dover flints $(<2 \mu \mathrm{m}$; Tullis and Tullis, 1972, Barber and Wenk, 1991) and Arkansas novaculite $(\sim 10 \mu \mathrm{m}$; Wenk et al., 2006), confirming that Dauphiné twinning can also be easily activated in coarse-grained material (Barber and Wenk, 1979; Wenk et al., 2007).

The consistency of the c-axis orientation distribution between starting material and the three stressed samples indicates that no dislocation plasticity was involved in the compression experiments. Twin domains may, however, show a different distribution of intracrystalline plastic deformation (Fall et al., 2016). For example, z-domains may act as preferred sites for dynamic recrystallization (e.g. Stipp and Kunze, 2008; Menegon et al., 2011). Therefore, the SGOA can have an added value in identifying $r$ - (twin) and $z$ - (host) domains.

The axial compression experiments have shown that Dauphiné twinning is easily activated and thus has a major influence on the rhomb orientation distribution. It therefore seems that Dauphiné twinning may seriously complicate the interpretation of quartz textures. It is not known how much of the rhomb preferred orientation is due to Dauphiné twinning and how much may be due to rhombohedral slip or effects of dynamic recrystallization.

\section{Conclusions}

With time-of-flight neutron diffraction and electron backscatter diffraction we have been able to correlate the evolution of the rhomb orientation distribution of quartz with the applied stress in axial compression experiments. From the bulk orientation distribution we can indirectly infer that Dauphiné twinning was induced already at $145 \mathrm{MPa}$ differential stress and saturated between $250 \mathrm{MPa}$ and $460 \mathrm{MPa}$ differential stress. The pole figure patterns show an increasing $\mathrm{r}$ rhomb maximum and $\mathrm{z}$ rhomb minimum parallel to the experimental axial compressive stress direction.

The newly developed SGOA gives the opportunity to separate DTBfree from DTB-containing grains and to study them in more detail separately. Grains with the pole to the negative $\mathrm{z}$ rhomb parallel to the applied axial compressive stress direction are in a highly favorable orientation to undergo Dauphiné twinning. Grains with the pole to the positive $r$ rhomb parallel to the applied axial compressive stress direction, on the other hand, are already in a stable orientation and do not twin. All grains with an intermediate orientation do not show a clear tendency to twin and remain largely unaffected during the compression experiments.

Using this principle, the SGOA of DTB-free grains can be used to identify the experimentally applied axial compressive stress direction. On the other hand, the SGOA of DTB-containing grains does not seem appropriate to identify the axial compressive stress direction. However, 
the SGOA of DTB-containing grains allows to distinguish between $r$ (twin) and z- (host) domains within the grain, which may have its implications in further deformation studies.

We believe that the SGOA has a potential as a paleostress indicator in quartz-bearing rocks, such as quartzites and quartz veins, that have not been affected by considerable crystal plastic strain. In the latter case, the SGOA, distinguishing twin from host domains, may be useful in constraining the role of Dauphiné twinning in crystal plastic deformation.

\section{Acknowledgements}

AM and MS acknowledges the financial support of the FWOVlaanderen (research project G097014N). HRW acknowledges support from NSF (EAR-1343908) and DOE (DE-FG02-05ER15637). SEM-EBSD measurements were done at EPS-Berkeley and we are grateful to Tim Teague who helped with experiments and sample preparation. Neutron scattering experiments were done at the HIPPO beamline of LANSCE, supported by DOE-BES. We are appreciative for constructive comments from the editor and the two reviewers, Geoff Lloyd and Holger Stünitz, that helped us to improve the manuscript.

\section{References}

Antao, S.M., Hassan, I., Wang, J., Lee, P.L., Toby, B.H., 2008. State-of-the-art high-resolution powder X-ray diffraction (HRPXRD) illustrated with Rietveld structure refinement of quartz, sodalite, tremolite, and meionite. Can. Mineral. 46, 150-1509.

Barber, D.J., Wenk, H.-R., 1979. Deformation twinning in calcite, dolomite, and other rhombohedral carbonates. Phys. Chem. Min. 5, 141-165.

Barber, D.J., Wenk, H.-R., 1991. Dauphiné twinning in deformed quartzites: implications of an in situ TEM study of the $\alpha-\beta$ phase transformation. Phys. Chem. Min. 17, 492-502.

Barton, N.R., Wenk, H.-R., 2007. Dauphiné twinning in polycrystalline quartz. Model. Simul. Mat. Sci. Eng. 15, 369-384.

Fall, E., Ukar, E., Laubach, S.E., 2016. Origin and timing of Dauphiné twins in quartz cement in fractured sandstones from diagenetic environments: insight from fluid inclusions. Tectonophysics 687, 195-209.

Friedel, G., 1926. Leçons de cristallographie. Berger-Levrault, Paris, pp. 602.

Frondel, C., 1945. Secondary Dauphine twinning in quartz. Am. Mineral. 30, 447-461.

Frondel, C., 1962. In: 7th Edtn. The System of Mineralogy, vol. 3 Wiley, New York.

Fynn, G.W., Powell, W.J.A., 1979. The Cutting and Polishing of Electro-optic Materials. Adams Hilger, London.

Heyliger, P., Ledbetter, H., Kim, S., 2003. Elastic constants of natural quartz. J. Acoust. Soc. Am. 114, 644-650.

Leydolt, F., 1855. Uber eine Methode, die Struktur und Zusammensetzung der Krystalle zu untersuchen. Ber. Ak. Wiss. Wien 15, 59.
Lloyd, G.E., 2004. Microstuctural evolution in a mylonitic quartz simple shear zone: the significant roles of Dauphiné twinning and misorientation. In: In: Alssop, G.I. (Ed.), Transports and Flow Processes in Shear Zones, vol. 224. Geological Society of London, Special Publication, pp. 39-61.

Lloyd, G.E., Freeman, B., 1994. Dynamic recrystallization of quartz and quartzites. J. Struct. Geol. 16, 867-881.

Menegon, L., Piazolo, S., Pennacchioni, G., 2011. The effect of Dauphiné twinning on plastic strain in quartz. Contrib. Mineral. Pet. 161, 635-652.

Ohno, I., Harada, K., Yoshitomi, C., 2006. Temperature variation of elastic constants of quartz across the $\alpha-\beta$ transition. Phys. Chem. Miner. 33, 1-9.

Paterson, M.S., 1970. A high-pressure, high-temperature apparatus for rock deformation. Int. J. Rock Mech. Min. Sci. 7, 517-526.

Schubnikov, A., 1930. Über Schlagfiguren des Quarzes. Z. Krist. 74, 103-104.

Schubnikov, A., Zinserling, K., 1932. Über die Schlag- und Druckfiguren und ueber die mechanischen Quarzzwillinge. Z. Krist. 83, 243-264.

Stipp, M., Stünitz, H., Heilbronner, R., Schmid, S.M., 2002. The eastern Tonale fault zone: a "natural laboratory" for crystal plastic deformation of quartz over a temperature range from 250 to $700^{\circ} \mathrm{C}$. J. Struct. Geol. 24, 1861-1884.

Stipp, M., Kunze, K., 2008. Dynamic recrystallization near the brittle-plastic transition in naturally and experimentally deformed quartz aggregates. Tectonophysics 448 , 77-97.

Thomas, L.A., Wooster, W.A., 1951. Piezocrescence-the growth of Dauphiné twinning in quartz under stress. Proc. R. Soc. Lond. A 208, 43-62.

Tochigi, E., Zepeda, E., Wenk, H.-R., Minor, A.M., 2014. In Situ TEM observation of plastic deformation in quartz. Phys. Chem. Min. 41, 757-765.

Tullis, J., 1970. Quartz: preferred orientation in rocks produced by Dauphiné twinning. Science 168, 1342-1344.

Tullis, J., Tullis, T.E., 1972. Preferred orientation produced by mechanical Dauphiné twinning. Thermodynamics and axial experiments. Am. Geophys. U. Monogr. 16, 67-82.

Van Landuyt, J., Van Tendeloo, G., Amelinckx, S., 1986. Reply to "Intermediate phase between the $\alpha$ and $\beta$ phases of quartz". Phys. Rev. B 34 (3), 2004.

Wenk, H.-R., Matthies, S., Donovan, J., Chateigner, 1998. BEARTEX: a Windows-based program system for quantitative texture analysis. J. Appl. Cryst. 31, 262-269.

Wenk, H.-R., Lonardelli, I., Vogel, S.C., Tullis, J., 2005. Dauphiné twinning as evidence for an impact origin of preferred orientation in quartzite: an example from Vredefort, South Africa. Geology 33, 273-276.

Wenk, H.-R., Rybacki, E., Dresen, D., Lonardelli, I., Barton, N., Franz, H., Gonzales, G., 2006. Dauphiné twinning and texture memory in polycrystalline quartz. Part 1: experimental deformation of novaculite. Phys. Chem. Min. 33, 667-676.

Wenk, H.-R., Bortolotti, M., Barton, N., Oliver, E., Brown, D., 2007. Dauphiné twinning and texture memory in polycrystalline quartz. Part 2: in situ neutron diffraction compression experiments. Phys. Chem. Min. 34, 599-607.

Wenk, H.-R., Barton, N., Bortolotti, M., Vogel, S., Voltolini, M., Lloyd, G., Gonzalez, G., 2009. Dauphiné twinning and texture memory in polycrystalline quartz. Part 3 : texture memory during phase transformation. Phys. Chem. Min. 37, 567-583.

Wenk, H.-R., Lutterotti, L., Vogel, S.C., 2010. Rietveld texture analysis from TOF neutron diffraction data. Powder Diffr. 25, 283-296.

Wenk, H.-R., Janssen, C., Kenkmann, T., Dresen, G., 2011. Mechanical twinning in quartz: shock experiments, impact, pseudotachylites and fault breccias. Tectonophysics 510, 69-79.

Zinserling, K., Schubnikow, A., 1933. Über die Pastizität des Quarzes. Z. Krist. 85, 454-461. 